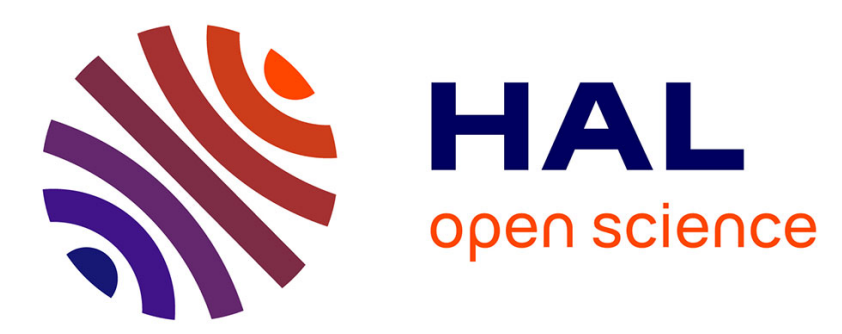

\title{
Roll manufacturing of polymer microfluidic devices using a roll embossing process
}

Jie Zhang, Mohamed Lakdhar Sahli, Jean-Claude Gelin, Thierry Barriere

\section{To cite this version:}

Jie Zhang, Mohamed Lakdhar Sahli, Jean-Claude Gelin, Thierry Barriere. Roll manufacturing of polymer microfluidic devices using a roll embossing process. Sensors and Actuators A: Physical , 2015, 230, pp.156-169. hal-02946386

\section{HAL Id: hal-02946386 \\ https://hal.science/hal-02946386}

Submitted on 23 Sep 2020

HAL is a multi-disciplinary open access archive for the deposit and dissemination of scientific research documents, whether they are published or not. The documents may come from teaching and research institutions in France or abroad, or from public or private research centers.
L'archive ouverte pluridisciplinaire HAL, est destinée au dépôt et à la diffusion de documents scientifiques de niveau recherche, publiés ou non, émanant des établissements d'enseignement et de recherche français ou étrangers, des laboratoires publics ou privés. 


\title{
Roll manufacturing of polymer microfluidic devices using a roll embossing process
}

\author{
J. Zhang ${ }^{1,2}$, M. Sahli $^{1^{*}}$, J-C Gelin ${ }^{1}$ and T. Barrière ${ }^{1}$ \\ ${ }^{1}$ Femto-ST Institute, Applied Mechanics Dept., CNRS UMR 6174, ENSMM, 25030 Besançon, France. \\ ${ }^{2}$ Femto-ST Institute, MN2S Dept., CNRS UMR 6174, 32 Avenue de l'Observatoire, Besançon,
} France.

*Corresponding author: Dr. SAHLI Mohamed

Mohamed.Sahli@ens2m.fr

Tél. +33381666040

\begin{abstract}
.
The replication of micro-fluidic devices is increasingly utilised in various industrial fields, such as medicine and cell biology research, and in many applications: drug screening, sugar testers, chemical microreactors, microprocessor cooling (just reward) and micro fuel cells. The roll embossing process $(R 2 R)$ is an efficient and economical method for fabricating micro/meso-features on the large-area surface of the polymer parts. In this work, we describe a roll embossing process for manufacturing micro-fluidic devices in different commercially available thermoplastic polymer using a micro-structured elastomeric pattern with low roughness $\left(R_{a}<50 \mathrm{~nm}\right)$ as a roller stamping tool. This work investigates the effect of processing parameters on material performance for manufacturing the micro-fluidic devices via a roll embossing process. They describes observations and surface topography analyses made to compare the replication quality of polymeric replicas obtained by filling micro-cavities using the roll embossing process. The results indicate that the variation in flow behaviour of polymer surface during roll embossing process is highly dependent on the forming temperature and rheological of polymer. In addition, the features of the elastomeric mould were replicated with good fidelity, retaining the original dimensions. By careful adjustment of process parameters, a micro-fluidic circuit with details in the range of $\mu m$ was successfully transferred onto different polymeric films.
\end{abstract}

Keywords: Roll embossing, flexible micro-fluidic device, flexible mould, roughness surfaces, rheological properties, polymers, silicon stamp, PDMS casting.

\section{Introduction}

Fabrication of microstructures can be performed by several methods including mechanical machining, lithographic processes and ion technologies. Most of these methods are relatively expensive and time consuming. Therefore, other technologies have emerged as polymer replication techniques, such as hot embossing and injection moulding, and have been successfully used in recent years in various cutting-edge industrial fields [1-4], for example, in the manufacturing of micro-fluidic chips [5-7]. Although hot embossing is the most simple and straightforward thermoplastic replication method, this technique suffers from long thermal cycles, which limits the mass production capability [8, 9]. Injection moulding is another polymer replication method can be used to fabricate polymer micro-fluidic devices for mass production purposes [10]. However, because of its comparatively high equipment cost, the requirement of the use of very high parameters process, and the robust micro-mould requirements, injection moulding is not widely applied in polymer micro-fluidic fabrication at the laboratory scale. 
The roller hot embossing method may be an alternative process to the hot embossing and injection method. It enables continuous processing of flexible sheets and film materials [11-15]. The roll embossing process has attracted attention due to its high volume production, reduced cycle time, and large area processing capability with an ease to manufacture and a relatively low investment cost [16-20]. The process also allows continuous or semi-continuous manufacturing, hence producing a very large number of devices with the same conditions in one run. An application field that could benefit from this manufacturing technology is micro-fluidics [21, 22], which is an enabling technology for lab-on-chip systems. Two possible configurations are available in roll-based embossing set-ups [23], roll-on-flat, where structures are patterned on a planar surface used as a stamping tool, and roll-to-roll, where features are either directly patterned on the roller or on a foil that is wrapped around one of the rollers to form an exchangeable tool on the embossing cylinder. Unlike hot embossing, roll embossing has the advantage of better uniformity, lower force, release of the trapped air bubbles, and the ability to repeat a stamp continuously on a large substrate. By fulfilling the aims of lower cost and higher throughput, roll-to-roll embossing is targeted to be a commercially viable method for the manufacture of micro- and nano-scale structures. Several types of thermoplastic materials that have been used in the hot embossing process are certainly well suited to roll embossing $[24,25]$.

Roll embossing of the polymer film substrate has been used in industry for a few decades, but scientific studies on the process have been rarely reported. Thomas Velten et al. [26] presented a new roll-to-roll embossing process allowing the replication of micro-patterns based on flexible silicon substrates with feature sizes down to $0.5 \mu \mathrm{m}$, a maximum depth of the embossed holes equal to $70 \%$ of the master height has been obtained. It turned out that the quality of replication strongly depends on the master structures itself. Yeo et al. [15] performed a series of experiments to investigate the micro-fabrication of polymeric devices using hot roller embossing. Both a higher process temperature and a higher process pressure were found to be usually required. Tan et al. [27] performed roller nanoimprint lithography on thin coatings of photoresist that are hundreds of nanometers in thickness. They reported the advantage of using a lower force over a large substrate. Recent studies have also reported that the imprinted microstructure is correlated to key process parameters, such as embossing temperature, roller speed, and roller embossing pressure. The influence of parameters such as roller temperature, applied pressure, roller speed and preheating of polymer substrate prior to embossing was also reviewed by various groups [24, 26, 28]. Metwally et al. [29] investigated the manufacturing of flexible devices in thermoplastic polymer foils by roll embossing using micro-structured Si mould inserts produced by a combination of Deep Reactive Ion Etching (DRIE) and RIE. The process was extended to produce sub-micron features. Yeo et al. [15] explored and discussed the effects of the process parameters, such as embossing pressure, substrate preheating, roller temperature and roller speed, on the embossed channel depth, with the goal of achieving process optimisation. Based on their results, they found that higher embossing pressure and preheating of the polymer substrate aids in improving the embossed channel depths. In addition, they also found that other factors, such as mould channel orientation and pattern density effects, were also pivotal in impacting substrate embossed depths. Mäkelä et al. [30] manufactured the display illumination device for backlight devices with high throughput and a low production using a high volume roll-to-roll imprinting process. They replicated successfully micron- and submicron-structured shapes of 
good homogeneity leading to the proper optical properties, thereby demonstrating the capability of the roll-to-roll process for producing devices with micron- and submicronscale optical structures with a high throughput and at a low production cost. Tsao et al., [20] presented a discussion on the effects of major process parameters on the imprinting performance. This study investigates a simple and rapid polymer replication method of manufacturing micro-channels by a hot roller embossing process. The results of this study reveal that the micro-channel depth and microchannel transfer efficiency increased as the rolling speed decreased and the embossing pressure increased. The proposed approach enables researchers to successfully fabricate polymer micro-fluidics using thermoplastic film at forming temperatures in the neighbourhood of the glass transition temperature of polymers. Unfortunately the imprinting process is not reliable in the reproduction of designs with a very high aspect ratio or nano-sized structures in this temperature range. Hence, interest exists to produce such structures by using molten polymers to exploit the very low viscosity. The main process of the roll embossing method is illustrated in Figure 1. Polymer material in form of pellets is fed into an extruder through a hopper. The material is then conveyed forward by a feeding screw and forced through a die to ensure the uniformity of thickness. Next, the material is structured by the embossing roller, followed by cooling via blown air or placement in a water bath. The elastomeric mould is wrapped on the embossing roller with micro-structure. Through the pressure, the molten polymer film is embossed and thus the microstructure on the elastomeric mould be transferred to the surface of the polymer film. After embossing, the polymer film with the micro-structure on its surface must be cooled down. During this cooling time, the polymer film must maintain good contact with the elastomeric roller to ensure the dimensional stability of the micro-structure while cooling. Finally, the polymer film with the micro-structure on its surface is de-moulded due to the flexibility of the roller.

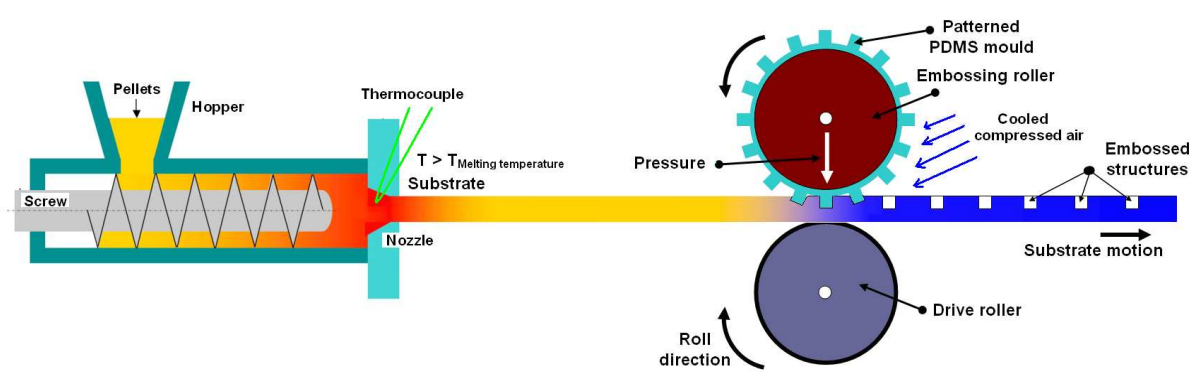

Fig. 1. Roll embossing process using a PDMS soft roller, as developed in our work.

The influence of parameters such as roller temperature, applied pressure, roller speed and preheating of polymer substrate prior to embossing was reviewed by various groups $[14,15,28]$. This paper aims to discuss a laboratory scale, the effects of varying the important process parameters, and the viscosity of polymer, on the final replication quality. In this work, we concentrate on optimizing four main factors: extrusion temperature, embossing pressure, roller speed and viscosity of a polymer. We report on our experiments of roll embossing using elastomeric stamp, starting by the manufacture of Si-moulds, followed by replication using PDMS casting, then micro structured in different substrates thermoplastic. Discussion of results will be performed in comparison with literature. The results show that the micro-structured silicone roller can be used for the manufacturing of the higher micro-fluidic mould cavities. This is made possible for a choice of rubber characterized by low viscosity 
for easy filling of mould cavities. This leads to reproduce of the master texturing with a below roughness surface of $0.05 \mu \mathrm{m}$. Other hand, an high hardness for a less deformation of the flexible mould during replication by the roll embossing process. In addition, it has been also shown In this study that a roughness of the micro-fluidic devices are sensibly depends on the forming temperature. The results concerning the filling of the micro-cavities provide information on the reliability of the process and provides insight into the potential to replicate surface geometries with complex topography.

\section{Materials and methods}

\subsection{Polymers}

Three polymers in the form of pellets were chosen for roll embossed micro-fluidic devices: two semi-crystalline polymers, low-density polyethylene (LDPE - 2022TN flexible and semi-opaque) and polypropylene (PP - EP548N - semi-rigid and opaque) made from granules from Sabic Innovative Plastics ${ }^{\circledR}$ and Cyclo-olefin copolymer (COC 5013 - rigid and transparent) provided by Topas Advanced Polymers ${ }^{\circledR}$. LPDE and PP have excellent chemical resistance properties and non-conducting electrical properties. However, PP shrinks too much when cooled down. They flow much easier in the melt resulting in lower processing temperature and pressures. COC, a highperformance amorphous ethylene copolymer, is resistant to a wide range of polar solvents and molecules. COC has good material properties, such as high transparency, low double refraction, low absorptive property, and biocompatibility. COC is suitable for use with visible and UV wavelengths. Table 1 presents the main material characteristics for replication.

Table 1. Material characteristics of different polymers

\begin{tabular}{|c|c|c|c|}
\hline Materials & $\begin{array}{c}\text { Low-Density } \\
\text { Polyethylene (LDPE) } \\
\text { LDPE 2022TN }\end{array}$ & $\begin{array}{c}\text { Polypropylene } \\
\text { (PP) } \\
\text { EP548N }\end{array}$ & $\begin{array}{c}\text { Cyclo-olefin } \\
\text { copolymer (COC) } \\
\text { COC } 5013\end{array}$ \\
\hline Density & 0.919 & 0.892 & 1.02 \\
\hline Transition temperature & -60 & -10 & 135 \\
\hline Melting temperature & 140 & 160 & - \\
\hline Thermal conductivity $\quad[\mathrm{W} / \mathrm{mK}]$ & 0.33 & 0.18 & 0.15 \\
\hline Specific heat & $1900-2300$ & $1700-1900$ & - \\
\hline Melt flow index & {$\left[230^{\circ} \mathrm{C} / 2.16 \mathrm{~kg}\right]: 23$} & {$\left[230^{\circ} \mathrm{C} / 2.16 \mathrm{~kg}\right]: 14$} & {$\left[260^{\circ} \mathrm{C} / 2.16 \mathrm{~kg}\right]: 48$} \\
\hline
\end{tabular}

\subsection{Roll embossing equipment}

We adapted extrusion equipment for fabricating polymeric micro-fluidic devices, as shown in Fig. 2. This equipment can handle material with a maximum width of 80 $\mathrm{mm}$ and at a maximum rolling speed of $1 \mathrm{~m} / \mathrm{min}$, which enables a high throughput of polymer chip pieces per hour when operated at optimum parameters. Temperature and pressure were controlled by a set of actuators, spaced uniformly along the slit. Thermocouples and pressure sensors were positioned close to the die. A collar heater, which could provide heating up to $350^{\circ} \mathrm{C}$, was also used to heat the die. In this study, a paper or rubber conveyor belt was used to avoid slippage, hooking, and shear of the polymer film during replication that may thus influence the microstructure transfer accuracy as well as the surface quality of the production. The process is different for hot embossing, where the polymer substrate is given ample time to heat and cool while force is still being applied. In hot roller embossing, the polymer is 
extruded through a die in the form of a film of $20-\mathrm{mm}$ width and $1-\mathrm{mm}$ thickness. Next, this thermoplastic sheet is passed between two rollers using a conveyor unit. The bottom roller is a rubber support roller, which is actively driven by the motor. The embossing roller (top roller) is a rigid mould, which is in turn passively driven by the support roller when the two rollers come into contact. When the substrate passes between the rollers, the mould features are embossed into it.

This roll embossing equipment enables rapid parameter variations at laboratory scale. The conveying speed can be varied from $0.1 \mathrm{~m} / \mathrm{min}$ up to $0.8 \mathrm{~m} / \mathrm{min}$; the pressure can be up to $0.2 \mathrm{MPa}$ and the temperature can be up to $350{ }^{\circ} \mathrm{C}$. The parameters were optimised in continuous roll embossing process. The main parameters are presented in Table 2 . Thermography images were obtained by a Cedip infrared camera of type Jad 3 with a macro-lens of type G3 with high resolution that ensures a precise thermal image acquisition at the exact point in time (thermal resolution of $20 \mathrm{mK}$, spatial resolution of $30 \mu \mathrm{m}$ ). Moreover, due to the integration of stationary infrared camera systems into the production processes, it is possible to regulate the temperature of the polymer extruded to address temperature deviations.

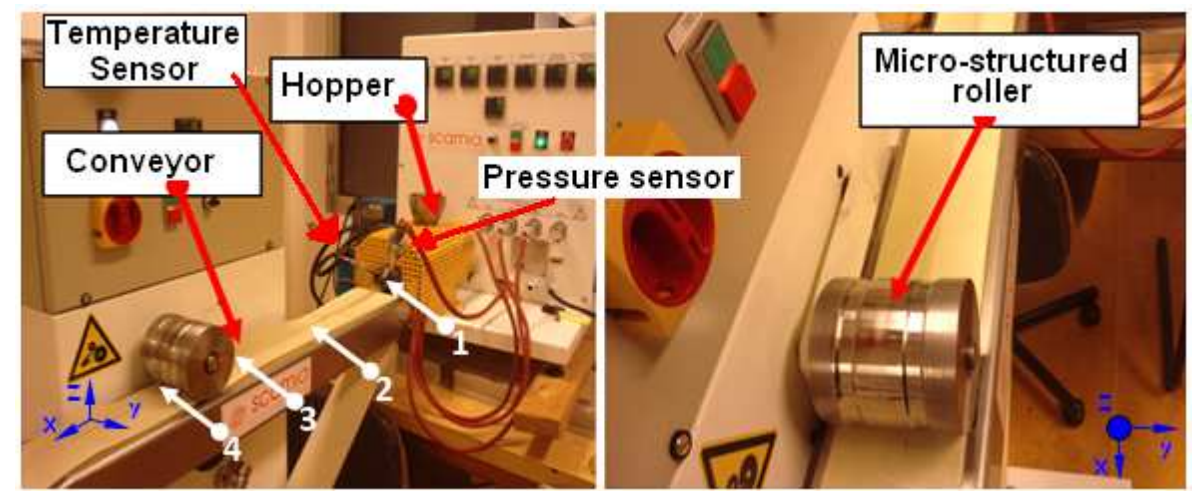

Fig. 2. (a) Hot roller embossing equipment (1: exit of the extrusion die, 2: half of the distance, 3 and 4: before and after their crushing), (b) Detail of embossing roller.

The temperature evolution of the elastomeric roller in zone 4, have been checked by using a thermal sensor. This probe is in direct contact with the extruded film (see diagram). A cycle of heat/cool has been tested: temperature ramp of $25^{\circ} \mathrm{C}$ to $180^{\circ} \mathrm{C}$ with heating rate equal to $5 \mathrm{C} / \mathrm{min}$ followed by coo ling using compressed air. The measured temperatures using thermocouple and that displayed by the thermal camera during tests are shown in Figure 3. These evolution profiles allow us to confirm the values displayed by the thermal camera with a gap of about $\pm 5^{\circ} \mathrm{C}$.

Table 2. Embossing process parameters.

\begin{tabular}{|lc|c|}
\hline Embossing parameter & Value \\
\hline Extrusion temperature & {$\left[{ }^{\circ}\right]$} & $T_{\text {extrusion: }}: 180-260$ \\
\hline Screw rotation speed & {$[\mathrm{rpm}]$} & $\mathrm{V}_{\text {extrusion }}: 10-100$ \\
\hline Roller speed range & {$[\mathrm{m} / \mathrm{min}]$} & $\mathrm{V}_{\text {roller }}: 0.1-0.8$ \\
\hline Adjusting range of the pressure & {$[\mathrm{MPa}]$} & $0.2-0.45$ \\
\hline
\end{tabular}




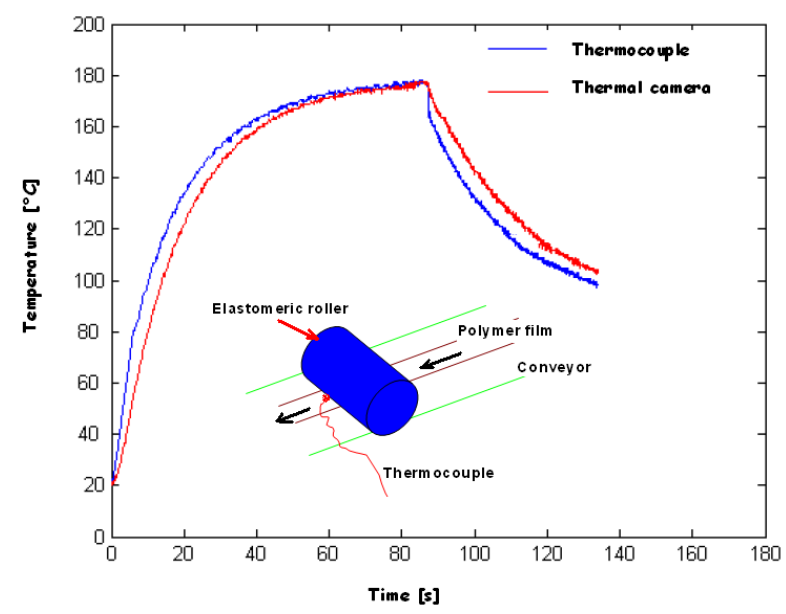

Figure 3. Profile of the temperatures evolutions.

\subsection{Elastomeric die mould cavities}

The silicon (Si) mould master was manufactured with micro-fluidic structures by means of photolithography and DRIE following the work of Metwally et al. [29]. The etched Si wafer, a.k.a. die, was then used as a mould to cast the complementary structures of the micro-fluidic device into silicone to obtain the elastomeric stamp that will be wrapped around the roller (Fig. 3).
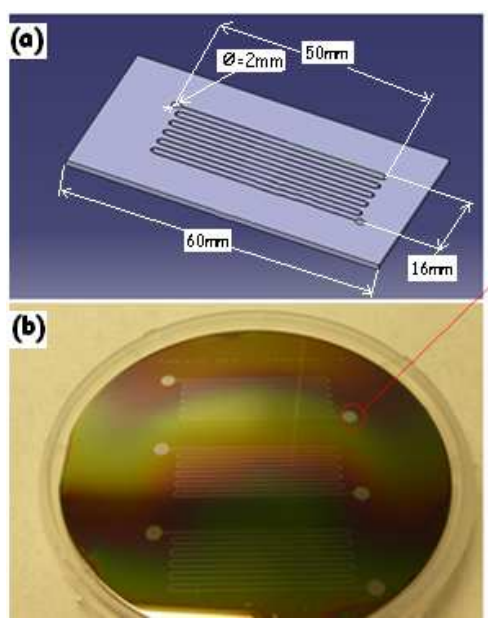
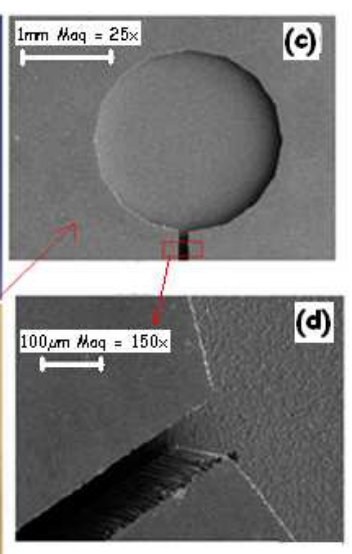

Fig. 3. (a) Sketch of the micro-fluidic pattern used in the study and a photograph of the silicon die mould, (b) picture of the micro-fluidic device containing micro-channels, (c) and (d) SEM micrographs of micro-reservoir whose diameter and depth were $2 \mathrm{~mm}$ and $110 \mu \mathrm{m}$, respectively, and a microchannel whose width and depth were $100 \mu \mathrm{m}$ and $110 \mu \mathrm{m}$, respectively.

In this study, several soft materials were selected in the casting of elastomeric replicas, such as room-temperature vulcanising (RTV) silicones on master moulds fabricated from photoresists on silicon substrates. Two criteria were imposed in our materials selection, either too low of a viscosity for easy filling of mould cavities and a high Shore hardness (Shore A) for minimal shrinkage and with less deformation of the flexible mould during replication by the hot embossing process. Based on these criteria, the M4370 A/B was selected for the PDMS casting (see Table 3). The silicone rubber (Elastosi ${ }^{\Theta} \mathrm{M} 4370 \mathrm{~A} / \mathrm{B}$ ) provided by Wacker ${ }^{\Theta}$ is composed of a silicone base and a catalyst and was used as the material for casting the elastomeric moulds. The silicone base and the catalyst were thoroughly mixed with a ratio 9 to 1 . The 
mixture was degassed for approximately 5 min in primary vacuum to remove air trapped in the silicone, which can lead to a porous matrix and defects in the resulting replicas. Next, the silicone is poured over the Si master and cured at $70{ }^{\circ} \mathrm{C}$ for $2 \mathrm{~h}$. The silicone can then be peeled off easily from the Si master. This elastomeric mould has one face that contains all of the details of the original master (Fig. 3a). The hardness of the mould was measured to be 55 Shore A. A simple roll embossing setup was developed, where the flexible mould with the micro-structured surface outside is mounted onto a metal cylinder and serves as the embossing master (also referred to as the cavity die mould) (Fig. 4).

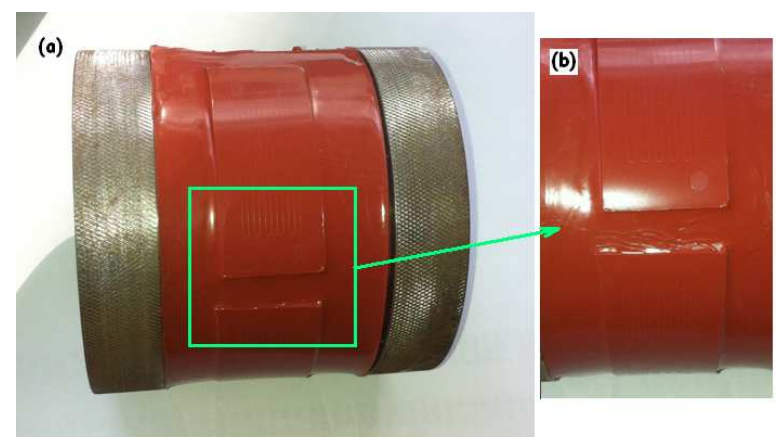

Fig. 4. (a) Embossing roller with the mounted flexible micro-fluidic mould and (b) two sets of microfluidic cavities using the elastomeric die mould.

Table 3. Material characteristics of the different silicones.

\begin{tabular}{|l|c|c|c|c|}
\hline Silicones & $\begin{array}{c}\text { Mixing ratio } \\
\mathbf{A}: \mathbf{B}\end{array}$ & $\begin{array}{c}\text { Viscosity at 23 } \mathbf{C} \\
{[\mathbf{P a . s}]}\end{array}$ & $\begin{array}{c}\text { Density at } \\
\mathbf{2 3} \mathbf{C} \\
{[\mathbf{g} / \mathbf{c m} 3]}\end{array}$ & $\begin{array}{c}\text { Hardness } \\
\text { Shore A }\end{array}$ \\
\hline M4370 A/B & $\underline{\mathbf{9 : 1}}$ & $\underline{\mathbf{6 . 0}}$ & $\underline{\mathbf{1 . 4 3}}$ & $\underline{\mathbf{5 5}}$ \\
\hline M4118 A/B & $1: 1$ & 2.5 & 1.10 & 20 \\
\hline M4125 A/B & $1: 1$ & 6.0 & 1.05 & 25 \\
\hline M4643 A/B & $9: 1$ & 25.0 & 1.35 & 48 \\
\hline M4470 A/B & 3 & 10.0 & 1.44 & 60 \\
\hline
\end{tabular}

Figure 5 illustrates the procedure for manufactured of an elastomeric roller with micro-fluidic patterns. The viscous polydimethylsiloxane (PDMS) pre-polymer solution (Sylgard 182) is poured into the silicon wafer (mould master). After the pre-polymer being cured, the PDMS substrate was peeled off from the mould master (see Fig. 5a). Then the micro-fluidic patterns were cut and oriented in the right direction and put in another rectangular mould for assemble all the patterns (see Fig. 5b). After, the micro-fluidic array was stuck on adhesive film, then directly wrapped onto a rigid cylinder, as shown in Fig. 5c to form a roller with micro-fluidic patterns. Finally, a soft PDMS roller with micro-fluidic cavity is successfully obtained.

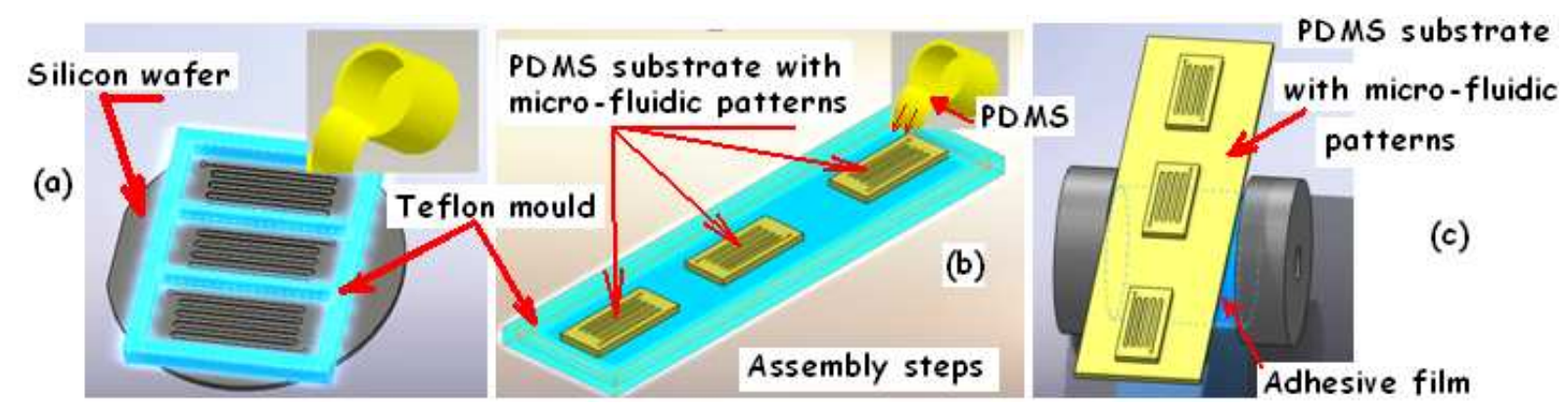

Fig. 5. Fabrication procedures of soft embossing roller with micro-fluidic cavities. 
The dimensions, surface roughness and surface topography of the elastomeric die mould and micro-fluidic samples were determined using an Alpha Step IQ profilometer with a diamond tip of $5-\mu \mathrm{m}$ radius operated with a scanning speed of 5 $\mu \mathrm{m} / \mathrm{s}$ on a length of $1-\mathrm{mm}$ inside and outside the reservoir pattern of 2-mm diameter on the elastomeric mould insert and the micro-system samples. Fig. 5 shows the cylindrical shape that corresponds to a future micro-reservoir of a micro-fluidic device. The shape is illustrated with a $30^{\circ}$ project ion angle, where the hidden faces are naturally not represented. They have been found that micro-fluidic patterns suffered not any degradation or dimensional and surface roughness variations.

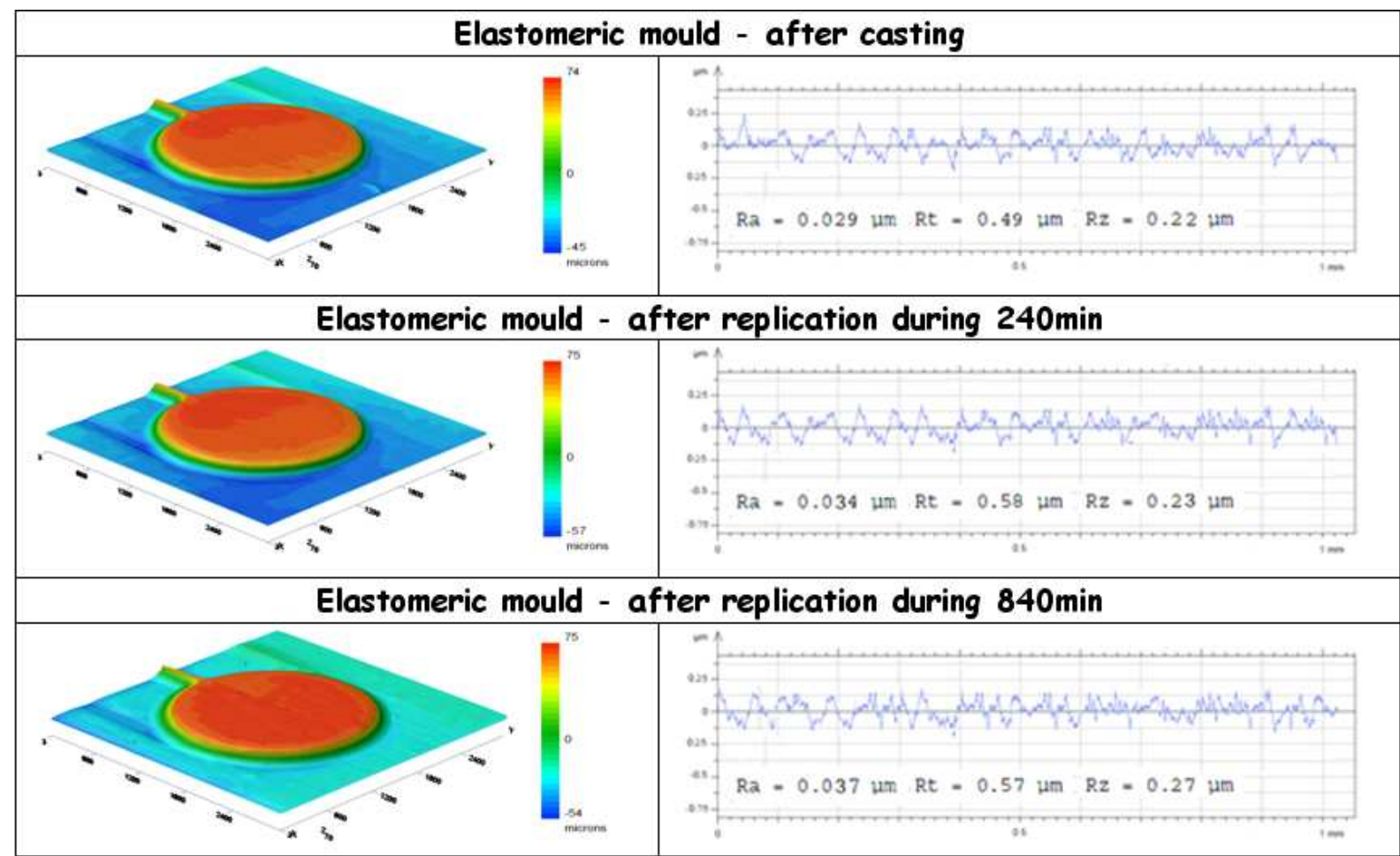

Fig. 5. 3D topography imprint of elastomeric cavity die mould realised by casting onto a Si wafer etched by DRIE (units: $\mu \mathrm{m}$ ).

\section{Results and discussions}

This section evaluates the effects of roller pressure, roller speed, roller temperature, extrusion temperature and extrusion speed on the micro-channel depth transfer efficiency. Process conditions must be determined that allow the surface to deform with good fidelity, while not affecting the shape of the thermoplastic replicas.

\subsection{Rheology characterisation of the polymers}

Viscosity shear measurements were performed in a controlled stress rheometer (Haake Mars III from Thermo Scientific ${ }^{\circledR}$ ) with a cone and plate geometry device (35$\mathrm{mm}$ diameter, $2^{\circ}$ cone angle and $0.106 \mathrm{~mm}$ gap). The test temperatures were in the range from $200{ }^{\circ} \mathrm{C}$ to $260^{\circ} \mathrm{C}$ that are well above mel ting or transition temperature of different polymers. The shear rate was chosen in a range from $10^{-1}$ to $10^{2} \mathrm{~s}^{-1}$. The samples were left to equilibrate for 5 minutes prior to the measurements. 
Fig. 6 shows the dependence of the melt shear viscosity of the PP polymer on the shear rate at the test temperatures of $200^{\circ} \mathrm{C}, 220^{\circ} \mathrm{C}, 240^{\circ} \mathrm{C}$ and $260^{\circ} \mathrm{C}$ and with shear rate range from $10^{-1}$ to $10^{2} \mathrm{~s}^{-1}$. The viscosity of PP melt is found to decrease strongly with an increase in the shear rate when $y$ is greater than $1 \mathrm{~s}^{-1}$. Fig. 6 also shows that the melt shear viscosity of PP polymer decreases with a rise of temperature when the shear rate is constant.

The rheological measurements were performed to characterise the polymers (PP, LDPE and COC) at the applied processing conditions (i.e., set temperature and shear rate). Fig. 7 shows the shear viscosity of various polymers at $260^{\circ} \mathrm{C}$ as a function of shear rate. The polymers exhibit pseudo-plastic behaviour, with a Newtonian plateau at lower shear rates and shear thinning behaviour at higher shear rates. The COC was found to exhibit the lowest viscosity.

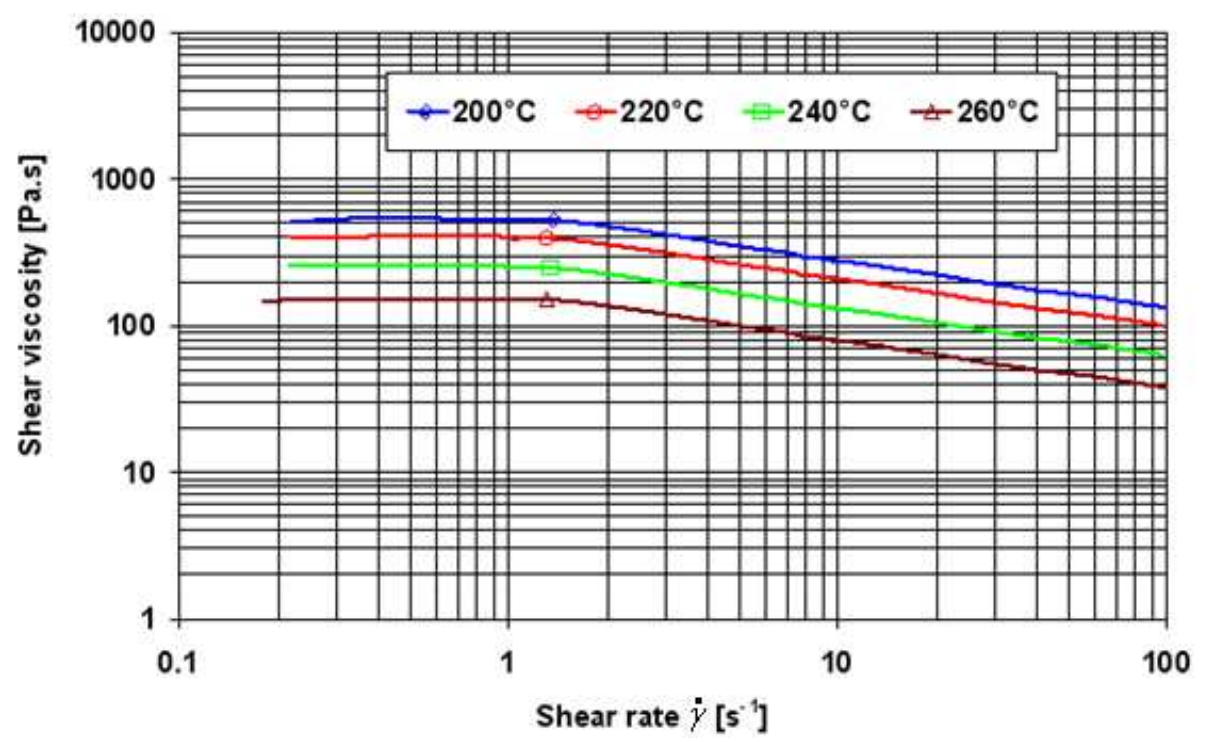

Fig. 6. Shear viscosity vs. shear rate for PP - EP548N at different temperatures.

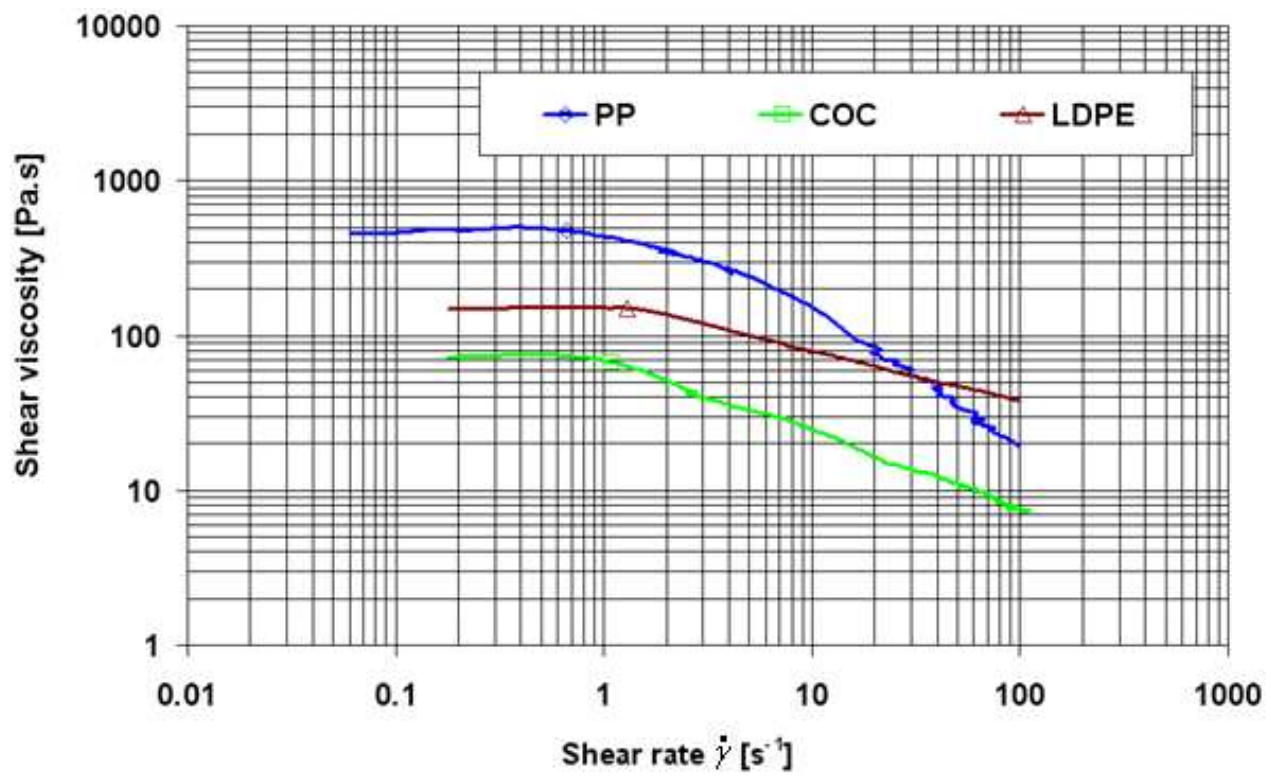

Fig. 7. Shear viscosity vs. shear rate for the three different polymers measured at $260^{\circ} \mathrm{C}$. 


\subsection{Analysis of the infrared imaging characteristics}

The most important parameters influencing the quality of the R2R structuring processes were the extrusion temperature, the roller speed and the roller pressure during the deformation. In addition, the properties of the equipment were of great importance. This section evaluates the effects of the extrusion temperature on the micro-channel depth transfer efficiency. This study used an extrusion temperature ranging from 160 to $260{ }^{\circ} \mathrm{C}$, a roller pressure in the range of 0.2 to $0.5 \mathrm{MPa}$, and a rolling speed in the range of 0.1 to $0.6 \mathrm{~m} / \mathrm{min}$ to study the embossing temperature effects.

First, we investigated the effects of the rolling and extrusion speeds on the temperature of polymer film substrate and geometry transfer efficiency. A series of tests were performed to avoid the unstable flow of the melt polymer through the die at high temperatures and pressures or longitudinal stretching. In a first attempt, the specimen surface temperature is tracked over four independent points (1: exit of the extrusion die, 2: half the distance, 3 and 4: before and after their crushing, see Fig. 4) using an infrared (IR) camera, as presented in Figs. 8, 9, 10 and 11. In this case, we extruded the films directly to obtain the desired width and thickness $(40 \mathrm{~mm}$ and 1 $\mathrm{mm}$ ). The extrusion temperature of polymer film during the roll embossing process (from the die outlet to the elastomeric roller) was very sensitive to the rolling speed. This trend was expected because a lower rolling speed increases the heat exchange, i.e., the time for transferring heat into the polymer film substrate surface during the hot roller embossing process is increased. The rolling speed can also cause polymer viscosity changes and flow disturbances during the R2R replication. The sample temperature was decreasing homogenously over the width of the thermoplastic substrate until $23 \%$ of the total extrusion temperature (see Figs. 8 and 9). However, the maximum observed temperature was $260^{\circ} \mathrm{C}$, which is quite moderate. Infrared imaging allows us to make adjustments to the process to improve the quality.
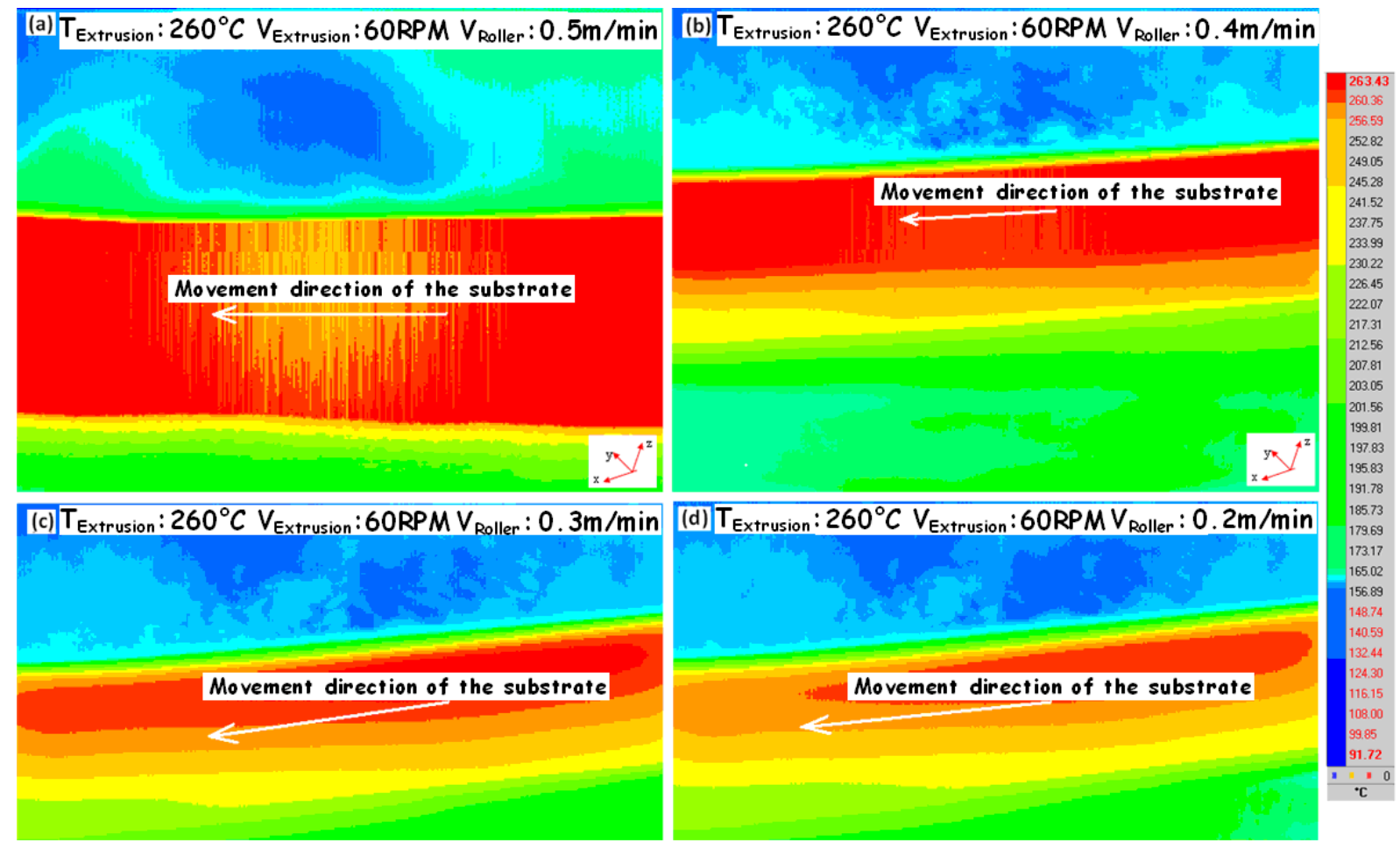

Fig. 8. Surface temperature of the samples measured at different roller speeds by infrared thermography over the same zone of the polypropylene substrates (2: half the distance). 

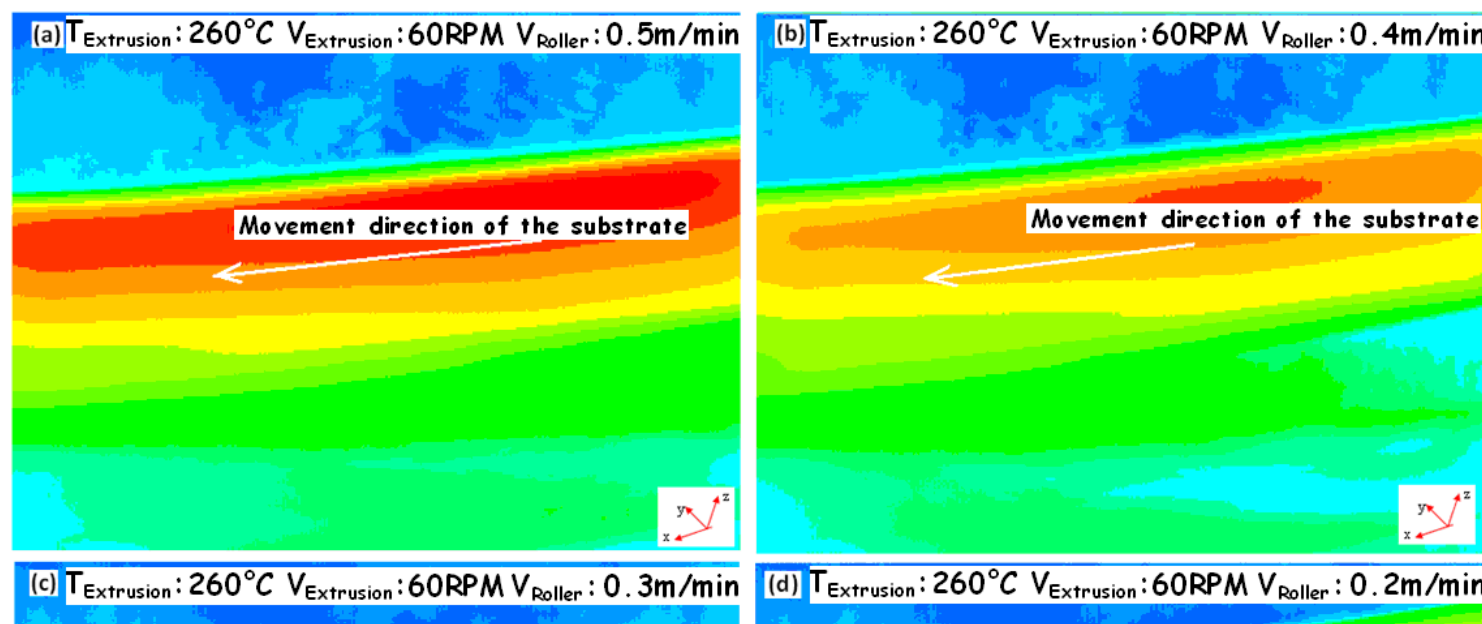

Movement direction of the substrate
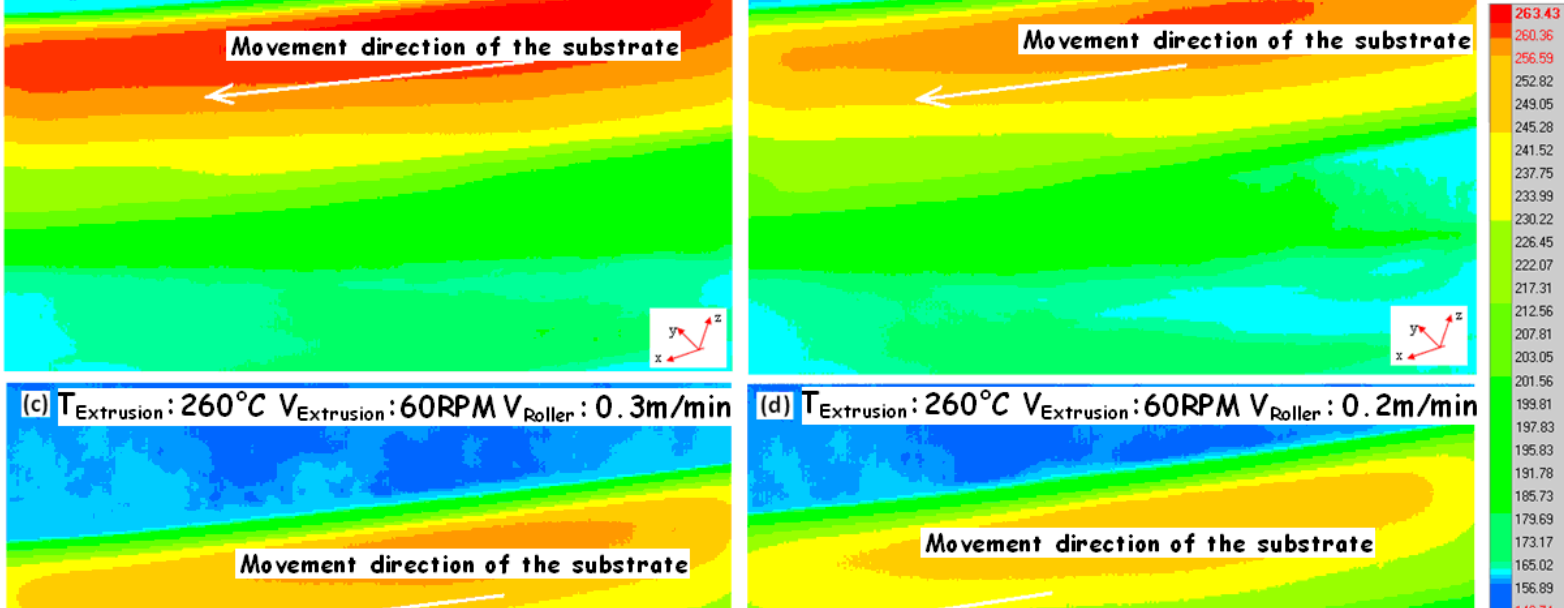

Movement direction of the substrate

Movement direction of the substrate
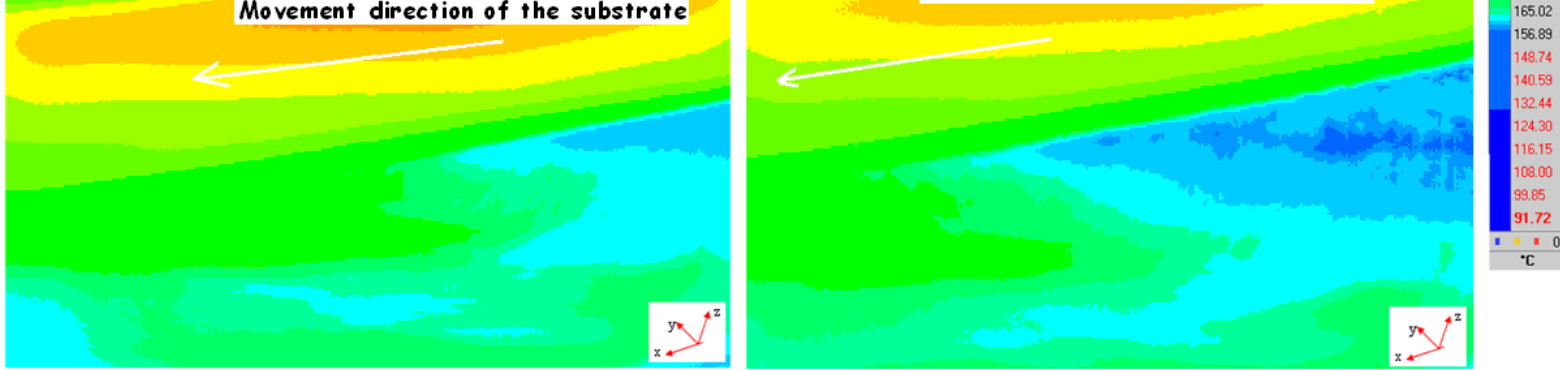

Fig. 9. Surface temperature of samples measured at different roller speeds by infrared thermography over the same zone of the low-density polyethylene substrates (2: half of the distance).

The polymer was extruded through a die in the form of thermoplastic sheet (see Fig. 10a), and then it was transported by a belt conveyor to have it pass between two rollers (see Fig. 10b); the thermoplastic sheet was micro-structured by the embossing roller (see Fig. 10c and 10d). The temperature is one of the most important parameters in roll embossing process. Figure 10 shows a molten polymer extruded through the die with an opening (Fig. 10a), then formed on our horizontal conveyor unit (Fig. 10b), and directly replicated at a given pressure using a micro-structured roller (Fig. 10c - before and after their crushing). Note that the temperature remains constant over the width of the polymer band and along the length travelled during the roll embossing, i.e., while passing the polymer film substrate below the elastomeric roller, before and after replication (see Fig. 4a).

After multiple replication tests, we found that the roller temperature is increased from room temperature to the extrusion temperature (via heat transfer between the hot substrate and the cold roller). However, this finding is due to the lack of a cooling system for the elastomeric roller. Under these conditions, the polymer cannot be solidified, which prevents the micro-fluidic shape imprinted by the flexible roller from being maintained in the polymer. The solution to this issue we propose is a cooling system using compressed air with a cooling air temperature and pressure equals to $20^{\circ} \mathrm{C}$ and 1 bar, respectively and a remote of $5 \mathrm{~mm}$ from the mould roller. This solution enables the reduction of the roller temperature to a temperature that is well below both the glass transition temperature and the melting temperature of the amorphous and semi-crystalline polymer. 

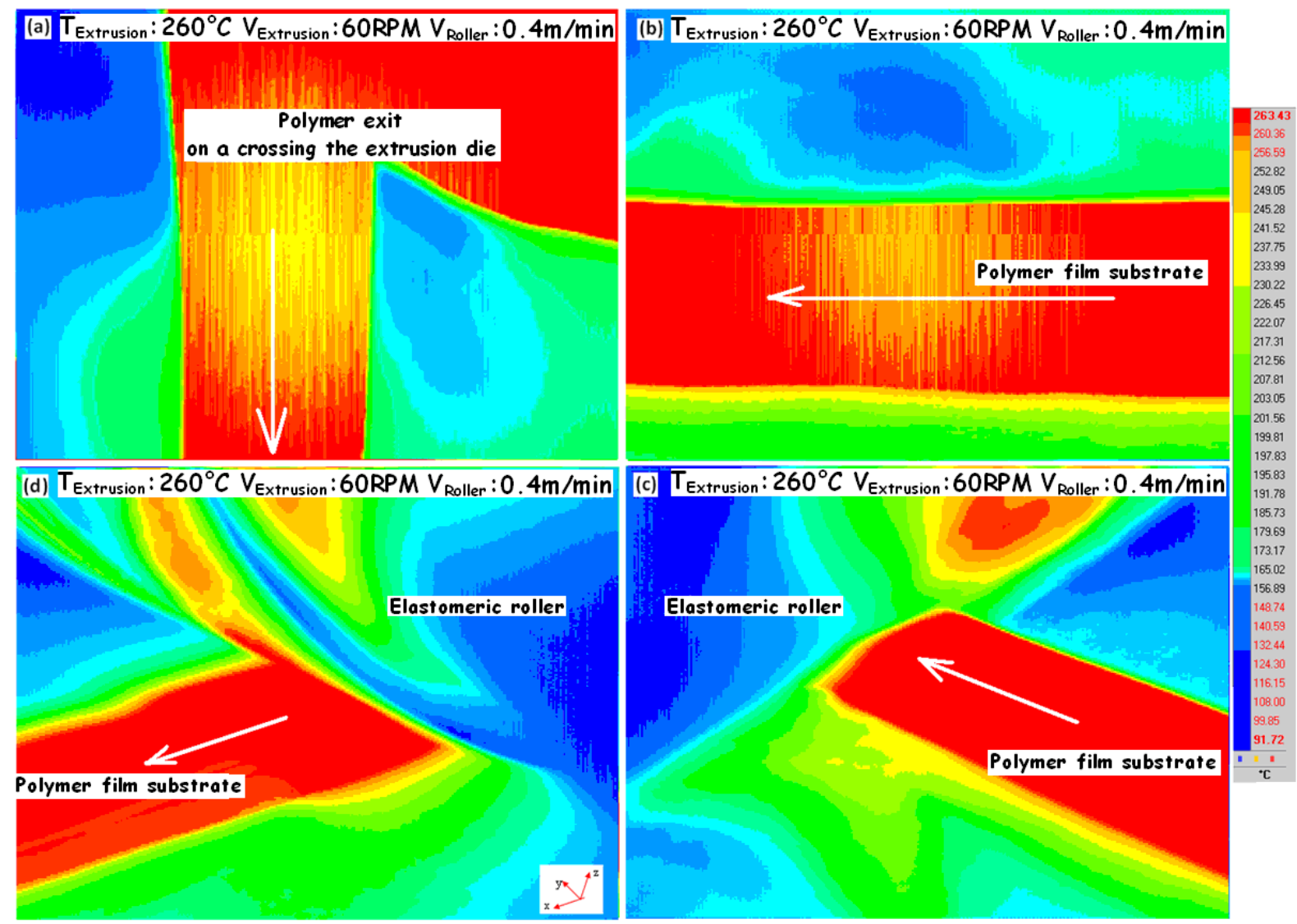

Fig. 10. Surface temperature of the samples measured using infrared thermography over four zones of the COC substrate held at $260^{\circ} \mathrm{C}$ : (a) extr uding the COC polymer in the molten state through an extrusion die, (b) passage of the molten polymer film substrate at the second control point of the conveyor, (c) and (d) molten thermoplastic flows through the elastomeric roller.

After the extrusion of the molten polymer through a flat die to form a melt film, after replication via the elastomeric roller, the polymer was rapidly quenched using forced air cooling. Four temperature measurements were performed with or without compressed cooling air, as shown in Fig. 11 (see Fig. 4, after their crushing). It is clear that the compressed air has allowed us to solve the heating problem of the roller, i.e., a melt film has quickly cooled down to enable the freezing of the microstructure. An infrared camera system was used in this work, which offers the advantage of providing a complete picture of the temperature distribution of the elastomeric roller or the polymer film with or without using blown air (see Fig. 11). From these measurements, one can conclude that an adjustment of the roller speed is necessary to improve the quality of the thermal exchange.

When the plastic films come into contact with the cool roller, energy is transferred to the film/roller interface to solidify the materials. After the solidifying of the polymeric materials, the plastic film is held between the rollers for a certain period for the purpose of microstructure conformity. A longer contact time between the flexible mould/polymer allows for more efficient cooling of the flexible mould and very rapid cooling of the film polymer at the same time. This will result in a further decrease of polymer viscosity, which translates to more efficient polymer flow behaviour and better mould filling [13]. A proper cooling of the COC film was achieved at the lowest rolling speed of $0.3 \mathrm{~m} / \mathrm{min}$. 


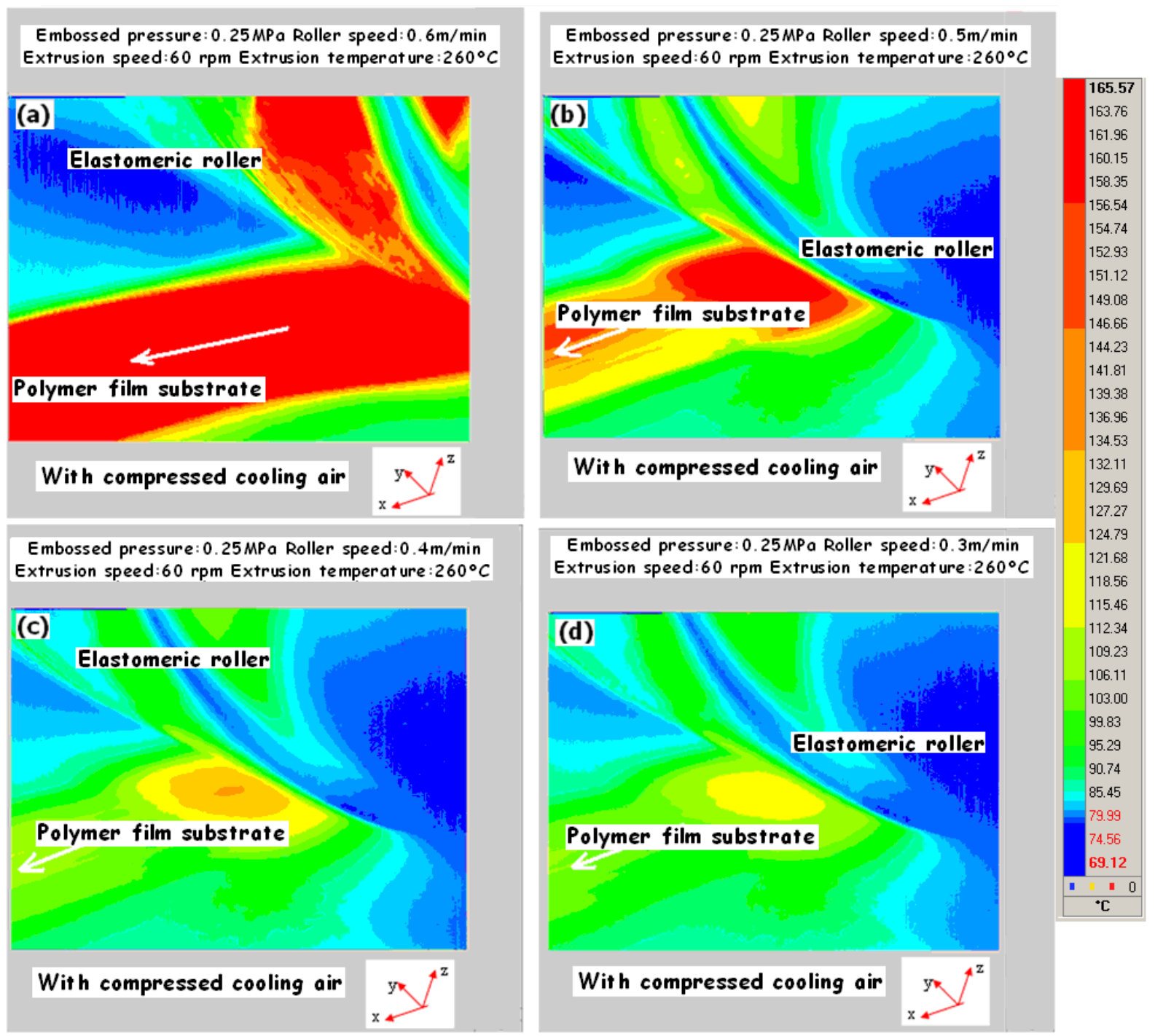

Fig. 11. Surface temperature of samples measured with or without compressed cooling air by infrared thermography over the same zone of the COC film (cooling air temperature: $20^{\circ} \mathrm{C}$, pressure: 1bar).

Two conveyor belts were tested in this study: a rubber belt and a paper belt. For example, Figs. $12 \mathrm{a}$ and $12 \mathrm{~b}$ show the proper facieses of roll embossing replication using a mechanical scanning profilometer (SMM) for the replicas obtained at the roller speeds equal to $0.4 \mathrm{~m} / \mathrm{min}$. Note that when we have used a rubber conveyor belt during roll embossing, the micro-fluidic systems were pulled back, thus resulting in a decrease in the embossed feature height. This conveyor type can generate a stretching of the plastic film together with a deformation of the microstructure shape. This stretching and deformation can also influence the microstructure transfer accuracy as well as the surface quality of the production. By adopting proper processing conditions, polymer substrates with micro-structures of good replication and with high dimensional uniformities could be obtained. This confirms the replicating capability by the assisted roll embossing technique proposed in this study.

Furthermore, the paper conveyor belt exhibits better the replicability, with the stretching of replicated shape of the microstructure being much reduced. The paper conveyor belt was finally selected for the remainder of the study. 

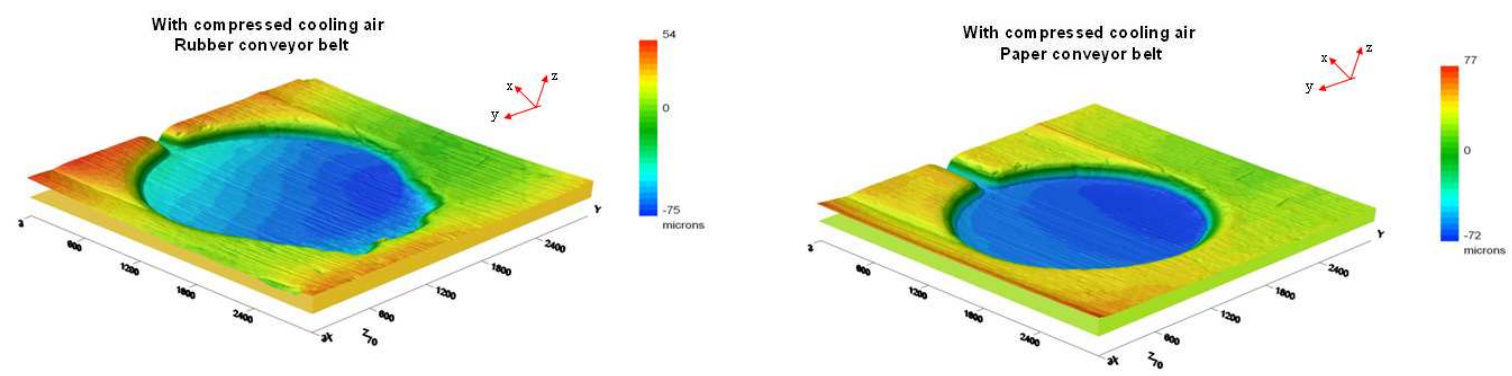

Fig. 12. 3D topographies imprint of a COC polymer replica realised by roll embossing. (Constant parameters: roller speed, $0.4 \mathrm{~m} / \mathrm{min}$; embossing pressure, $0.25 \mathrm{MPa}$; extrusion temperature, $260^{\circ} \mathrm{C}$ ), units: $\mu \mathrm{m}$.

\subsection{Effects of extrusion temperature}

The extrusion temperature dominates the deformation properties of the polymer. The extrusion temperature is chosen to be above the melting temperature and below the decomposition temperature. While at low temperatures, deformation becomes difficult, temperatures that are too high increase the risk of creasing the polymer foil; as a result, a reasonable compromise must be found. The extrusion temperature was increased gradually from 160 to $260^{\circ} \mathrm{C}$ in order to examine the possibility to replicate the stamp with good fidelity while limiting the thermal shrinkage as much as possible.

Figure 13 presents the experimental results. The micro-channel depth transfer efficiency, defined as the average depth of the embossed micro-channel divided by the elastomeric mould height, was obtained from five different measurements. The averages values of the micro-channels depth have been measured using different zones several on micro-canals of five micro-fluidic devices. For the COC substrate depicted in Fig. 13, the average depth of the roll embossed measured from $37.3 \pm 0.9$ to $108.8 \pm 1.9 \mu \mathrm{m}$ over the extrusion temperature range of 180 to $260{ }^{\circ} \mathrm{C}$. When the roll embossing temperature exceeded the $240^{\circ} \mathrm{C}$ thre shold, the average depth of the embossed micro-channel increased close to the mould depth of $110 \mu \mathrm{m}$. When the extrusion temperature was set between $180^{\circ} \mathrm{C}$ and $190^{\circ} \mathrm{C}$, only $34-40 \%$ depth transfer efficiency was achieved, according to the polymer used in the replication test. When the extrusion temperature exceeded the $220^{\circ} \mathrm{C}$ threshold, the COC substrate surface surpassed its $\mathrm{T}_{\mathrm{g}}$ point, and the resulting $\mathrm{COC}$ polymer reflowed into the mould cavities more effectively. The overheated polymers reflow tended to stick to the roller mould after heating above $260^{\circ} \mathrm{C}$. In this case, the temperature reached the limits of the cooling system used in this process. The solution to this problem consists of using cooling in a closed circuit. Similar experimental observations were made for the roll embossed PP and LDPE substrates (Fig. 13). As the embossing temperature increased to $240{ }^{\circ} \mathrm{C}, 97.3 \%$ micro-channel depth transfer efficiency $(107.7 \pm 0.7 \mu \mathrm{m})$ was achieved using the PP or LDPE substrates. Viscoelastic behaviour of polymer during micro-replication process is strongly dependent on the temperature and thus determines the surface morphology [9, 10].

Figure 14 shows variations of the average depths versus embossing temperatures ranging from 180 to $260^{\circ} \mathrm{C}$ with the pressure and speed roller set to $0.25 \mathrm{MPa}$ and $0.6 \mathrm{~m} / \mathrm{min}$, respectively. As shown in Figure 14, the mould cavities could be fully filled and the grating structure is well-defined after embossing at $260^{\circ} \mathrm{C}$ [4]. The temperature is one of the most important parameters in the roll embossing process. If the temperature of the polymer film is too low, insufficient liquidity of the polymer occurs, resulting in the incomplete filling of the elastomeric roller and a large elastic recovery of the micro-structure after de-moulding; for example, the embossed 
average depth of COC substrate decreases from 76.8 to $37.3 \mu \mathrm{m}$ when the extrusion temperature was reduced from 200 to $180^{\circ} \mathrm{C}$. In cont rast, if the temperature of the polymer film is too high (near degradation), the structure of the polymer chain can be destroyed, thereby generating many defects on the micro-structure. This is in agreement with the previous report by Scheer and Schulz indicating that embossing of the grating structure above the viscous-state temperature could result in a significantly increased incidence of defective gratings [12].

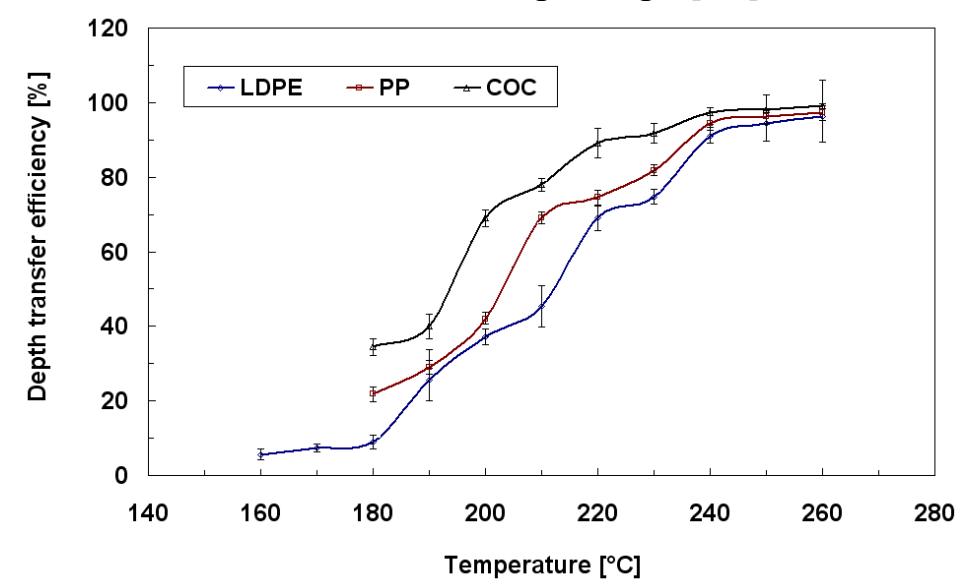

Fig. 13. Effect of extrusion temperature on the average depths of the micro-channel of the different substrates (constant parameters: rolling speed, $0.4 \mathrm{~m} / \mathrm{min}$; rolling pressure, $0.35 \mathrm{MPa}$ ).

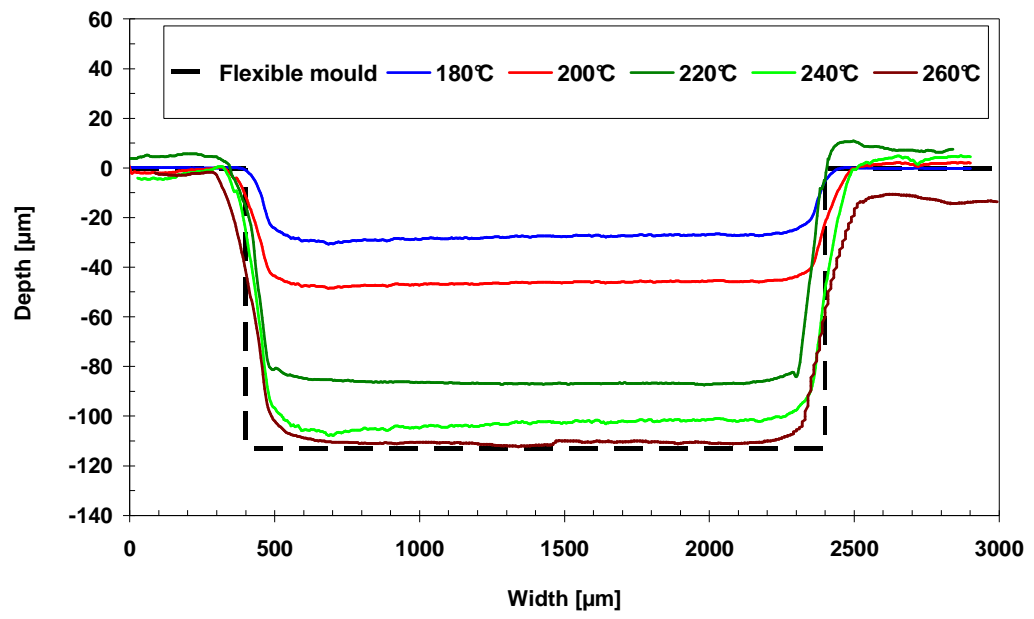

Fig. 14. Effect of extrusion temperature on the cross-sectional profile of the PP film at different temperatures (constant parameters: rolling speed, $0.4 \mathrm{~m} / \mathrm{min}$; rolling pressure, $0.35 \mathrm{MPa}$ ).

\subsection{Effects of roller speed}

The experiments in this study were performed with eight different rolling speeds ranging from 0.1 to $0.8 \mathrm{~m} / \mathrm{min}$, with a $0.4 \mathrm{MPa}$ embossing pressure and optimised embossing temperatures of $240{ }^{\circ} \mathrm{C}$ for the different polymers. For low rolling speeds from 0.1 to 0.2 , the materials at the film/roller interface were not completely melted (polymer film arrived with some already solidified part). The replicability of the embossed films decreases accordingly. In contrast, although a very high rolling speed leads to an enhanced production throughput, it generates a uniaxial stretching of thin thermoplastic film, resulting in the deformation of micro-fluidic pattern with depth variation. For low-to-moderate rolling speeds, the replicated depths increased with the rolling speed for the roll-to-roll embossing facility used in this study. 
Figure 15 shows that a value of the micro-channel depth transfer efficiency of nearly $100 \%(109.9 \pm 1.4 \mu \mathrm{m}$, average depths) was achieved at the lowest rolling speeds of $0.3,0.4$ and $0.5 \mathrm{~m} / \mathrm{min}$ for the COC, PP and LDPE films, respectively. When the roller speed increased (as shown in Fig. 15) from 0.1 to $0.5 \mathrm{~m} / \mathrm{min}$, the embossed depth increased from approximately 58 to $109.8 \mu \mathrm{m}$. However, a higher rolling speed with a lower extrusion speed causes a stretching of the polymer substrate during the hot roller embossing process. For example, the depth transfer efficiency of the COC substrate decreased to only $90 \%$ at the highest rolling speed of $0.8 \mathrm{~m} / \mathrm{min}$. This variation is due to the stretching rate of the substrate and is related to a balance between the extrusion speed and roller speed. For example, the transfer efficiency of LDPE decreased to $99 \%, 60 \%$, and $39 \%$ as the rolling speed increased to $0.6 \mathrm{~m} / \mathrm{min}, 0.7 \mathrm{~m} / \mathrm{min}$, and $0.8 \mathrm{~m} / \mathrm{min}$, respectively. This is in agreement with the previous work by $\mathrm{K}$. Metwally et al., indicating that embossing of the microchannels were successfully replicated by roll embossing in Topas 8007 COC and PMMA, with a single pass, using a dry-etched flat Si-mould [29].

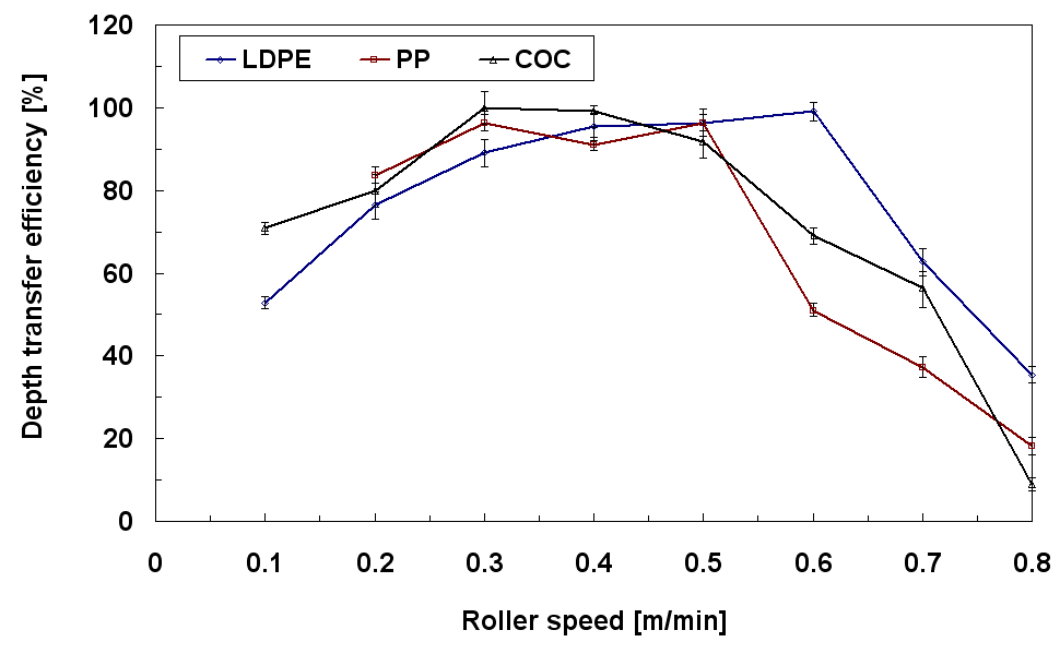

Fig. 15. Effect of the rolling speed on the average depth of the micro-channel for the different polymer film substrates. The elastomeric micro-channel mould height was $110 \mu \mathrm{m}$.

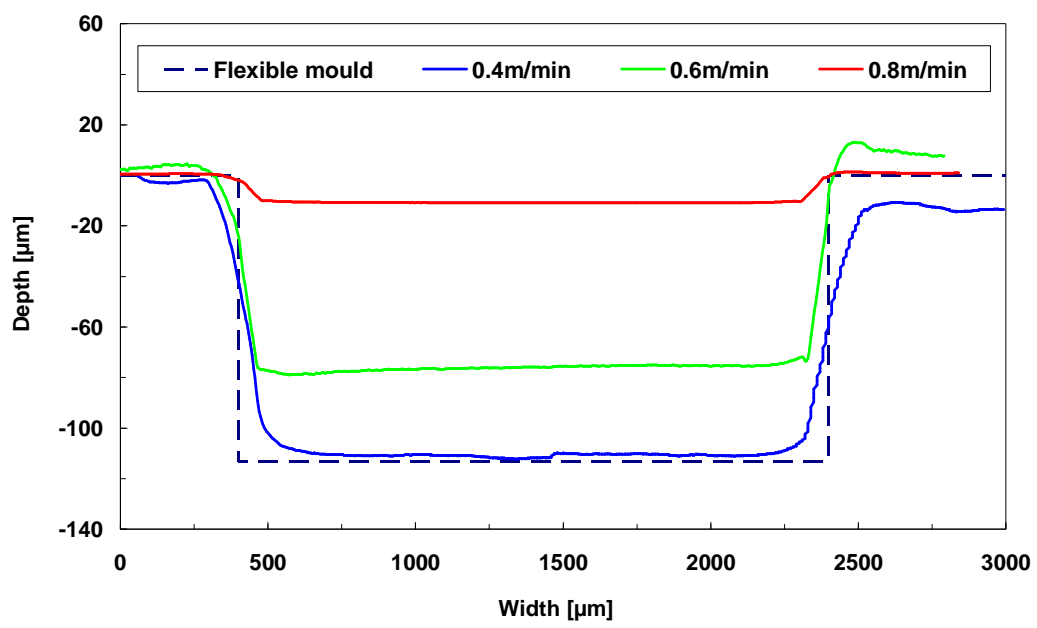

Fig. 16. Effect of rolling speed on the cross-sectional profile of a COC film. Constant parameters: roller temperature $240^{\circ} \mathrm{C}$; roller pressure, $0.4 \mathrm{MPa}$ ).

Figure 16 shows the visible effect of the rolling speed on the cross-sectional profiles of a COC film. When the rolling speed is $0.4 \mathrm{~m} / \mathrm{min}$, the micro-channel is 
almost replicated, the transfer efficiency is nearly $100 \%$, and a proper filling is achieved; with the increasing of the rolling speed, the filling effect became worse, and when the rolling speed is the maximum test speed $(0.8 \mathrm{~m} / \mathrm{min})$, the transfer efficiency is only $15 \%$ and the replication is impossible.

\subsection{Effects of roller pressure}

The pressure was the other important parameter in the roll embossing process. On one hand, if the pressure was too low, incomplete filling of the elastomeric roller cavities occurred. On the other hand, if the pressure was too high, it will generate residual stress in the final products and deformation of the product occurred after demoulding. The uneven distribution of the pressure will lead to a poor distribution of the micro-structure and cause the mould to be easily damaged. The experiments in this study were conducted at five different embossing pressures $(0.25 \mathrm{MPa}, 0.30$ $\mathrm{MPa}, 0.35 \mathrm{MPa}, 0.40 \mathrm{MPa}$ and $0.45 \mathrm{MPa}$ ) to investigate the average depth of the micro-channel and geometry transfer efficiency. The optimised rolling speeds of 0.3 $\mathrm{m} / \mathrm{min}$ with $240{ }^{\circ} \mathrm{C}$ extrusion temperature were used to study the pressure effects. Figure 17 shows the effect of embossing pressure on the depth transfer efficiency and the different filling sensitivities for different embossed thermoplastic substrates [13]. For example, for a COC substrate, a depth transfer efficiency of only $59.4 \%$ $(65.4 \pm 0.5 \mu \mathrm{m})$ was achieved at $0.25 \mathrm{MPa}$, and the efficiency increased to $63 \%(69.4$ $\pm 1.6 \mu \mathrm{m}), 86.4 \%(95.2 \pm 0.9 \mu \mathrm{m}), 95.6 \%(105.2 .1 \pm 3.3 \mu \mathrm{m})$ and $99.45 \%(109.4 \pm 1.6$ $\mu \mathrm{m})$ for roller pressures of $0.30 \mathrm{MPa}, 0.35 \mathrm{MPa}, 0.40 \mathrm{MPa}$ and $0.45 \mathrm{MPa}$, respectively. The maximum pressure of $0.45 \mathrm{MPa}$ achieved $\approx 100 \%$ micro-channel transfer efficiency with a depth of $109.4 \pm 1.6 \mu \mathrm{m}$.

Figure 18 shows the change in embossing pressure vs. the channel depth. By increasing the embossing pressure from 0.1 to $0.5 \mathrm{MPa}$ and keeping the other parameters constant, the embossed depths clearly increased from 65.4 to $86.4 \mu \mathrm{m}$. Higher embossed depths were achieved because higher embossing pressure promoted faster polymer flow. The COC substrate embossing pressure cross-section relationship displayed in Fig. 18 indicates that the average depth of the channel increased in conjunction with the embossing pressure. Micro-channel imprints appeared when the roller force exceeded $0.15 \mathrm{MPa}$, and the embossed depth increased with the roller force. A roller pressure greater than $0.25 \mathrm{MPa}$ leads to approximately $65.4 \mu \mathrm{m}$ (59.4\%). Insufficient heating and pressure application may result in incomplete replicas. Good micro-channel pattern transfer was found at the maximum pressure of $0.45 \mathrm{MPa}$. The extrusion temperature, rolling speed, and roller pressure experiments above revealed the hot roller embossing temperature $\left(240{ }^{\circ} \mathrm{C}\right.$ for COC, $240{ }^{\circ} \mathrm{C}$ for PP and $260^{\circ} \mathrm{C}$ for LDPE), rollin $\mathrm{g}$ speed $(0.3 \mathrm{~m} / \mathrm{min}$ for COC, 0.3 $\mathrm{m} / \mathrm{min}$ for PP and $0.5 \mathrm{~m} / \mathrm{min}$ for LDPE), and embossing pressure $(0.4 \mathrm{MPa})$ required for optimal imprinting efficiency. It is well known that the filling of mould micro-cavities can be improved by: increasing the forming temperature which decreases the polymer viscosity, applying a higher pressure, reducing the feed rate, and increasing the number of passes [12]. 


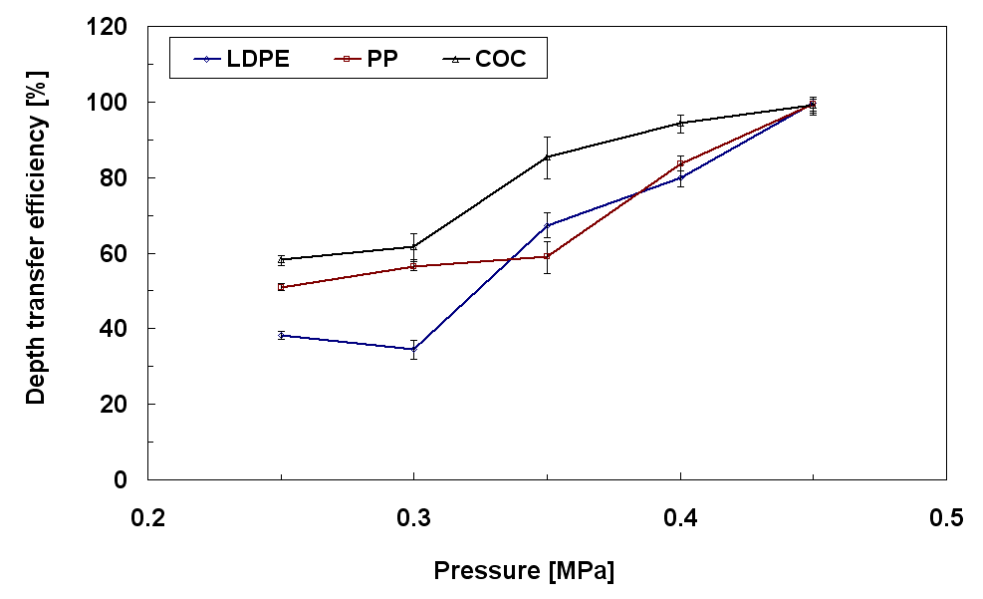

Fig. 17. Effect of embossing pressure on the average depth of the micro-channel for the different polymer film substrates. The elastomeric micro-channel mould height was $110 \mu \mathrm{m}$.

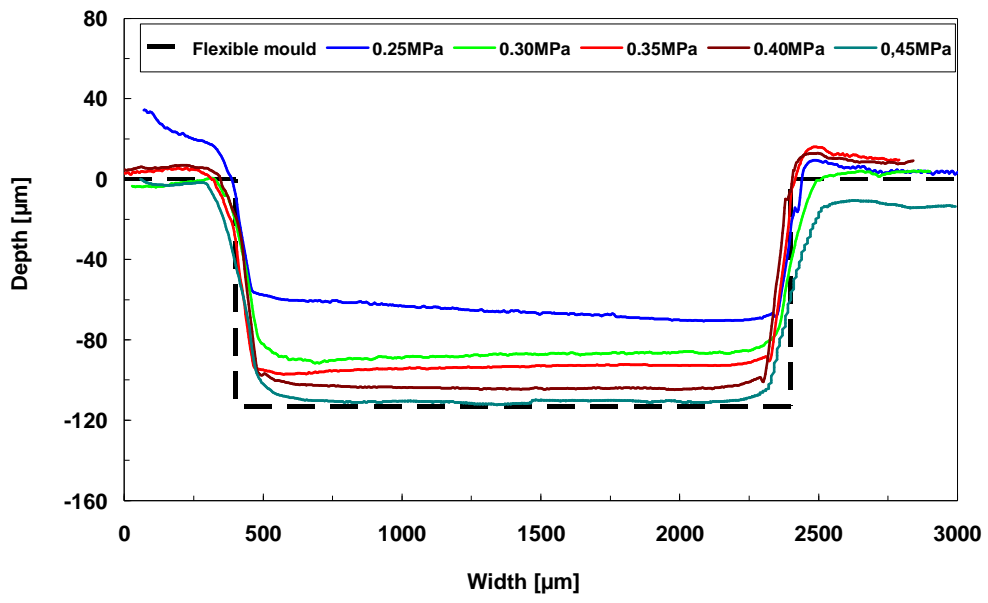

Fig. 18. Effect of embossing pressure on the cross-sectional profile of a COC substrate (constant parameters: roller temperature $240{ }^{\circ} \mathrm{C}$; roller speed, $0.3 \mathrm{~m} / \mathrm{min}$ ).

The reservoir of the micro-fluidic devices replicated using roll embossing process is shown in Figure 19. The grating structures were well replicated, and the height was relatively close to that of the structure of the elastomeric roller. The measurement is assessed by comparing the measurement with roughness of elastomeric roller and replicas. It was found that the surface roughness of the micro-structured replicas obtained by roll embossing is significantly affected by parameters process/material, ie, the forming temperature and the melting temperature of polymer. The surface roughness was found to be quite low $\left(R_{a}<0.1 \mu \mathrm{m}\right)$. Furthermore, as has been shown in previous work [15], the aspect ratio, and not the resolution, can be seen as the limiting factor for replication when sub-100 $\mathrm{nm}$ structures have to be embossed. However, due to structure degradation, careful setting of parameters is needed to keep structural loss below tolerances. E.g. the use of flexible mould made using silicon master has solved part of the problem. Figure 20 shows some of the samples after roll embossing. When the COC substrate was heated to above its $T_{\mathrm{g}}$ of $120^{\circ} \mathrm{C}$ [4] and with adequate embossing pressure and time, the elastomeric mould features were transferred. 

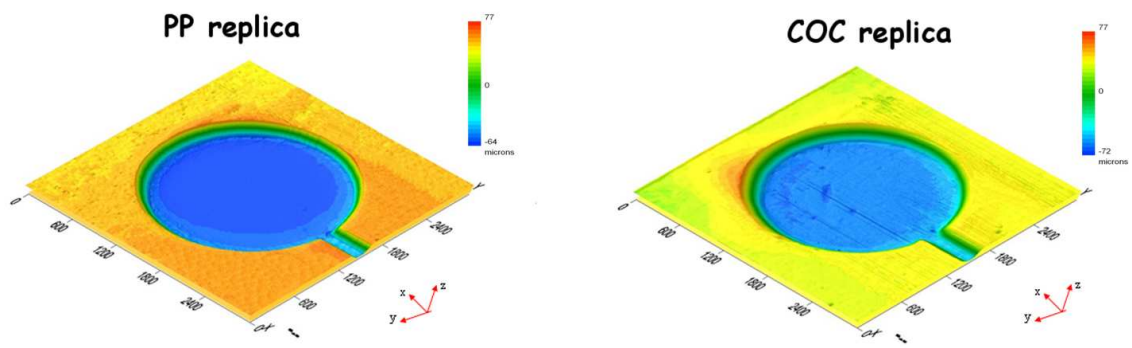

Roller pressure: $0.4 \mathrm{MPa}$; Roller speed: $0.5 \mathrm{~m} / \mathrm{min}$

Extrusion temperature: $240^{\circ} \mathrm{C}$; Extrusion speed: $60 \mathrm{rpm}$

Fig. 19. 3D topography imprints of PP and COC polymer replicas realised by roll embossing.

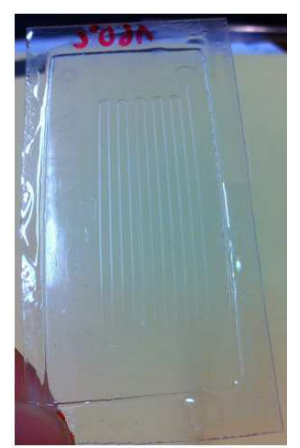

Fig. 20. Roll embossed micro-fluidic devices.

Si moulds have very short lifetimes even though they have various advantages. Therefore, elastomeric moulds can be used as an alternative for fabrication of polymeric micro-fluidic devices. The schematic diagram of micro-structured mould shown in Fig. 21a illustrates various critical features such as parallel channels, $U$ shape sections and O-shape reservoirs. The protruded sidewalls of the microchannels have a square cross section with the width and height being $100 \mu \mathrm{m}$. The spacing between the neighbouring protrusions is $500 \mu \mathrm{m}$. The SEM micrographs in Fig. 21b-d show the various features of a COC micro-fluidic device manufactured using an elastomeric mould from its R2R replication. A better replication quality is observed from the $\mathrm{COC}$ products manufactured using an elastomeric mould as shown in Fig. 21.

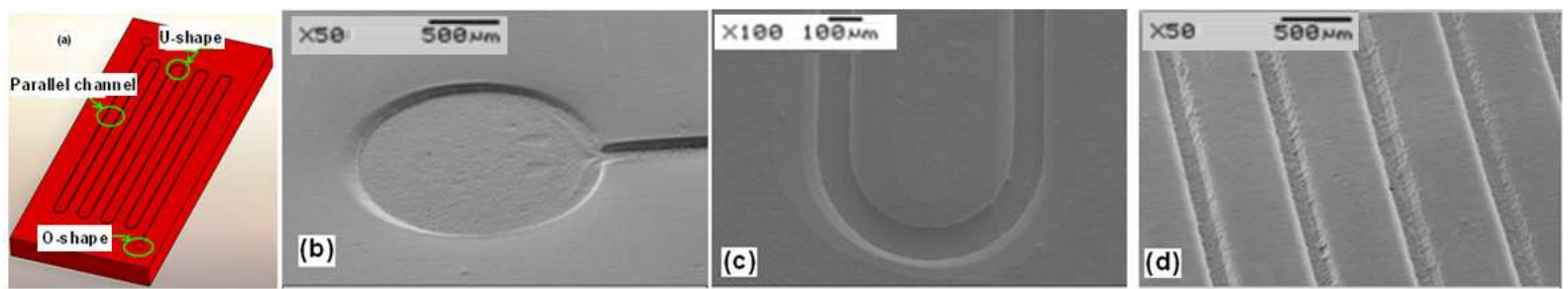

Fig.21. (a) Schematic diagram of micro-fluidic mould, (b) and (c) SEM micrographs of $O$ and $U$ shaped features and (d) parallel channels of a COC device manufactured using PDMS mould.

Surface roughness is important parameter of characterization of micro component in which it affects its performance during working. Therefore, the surface roughness was investigated in this work using a mechanical profilometer. The roughness parameter $\left(R_{a}\right)$ was measured on top surface of the micro-replicas. The surface roughness variations of the die mould cavities and replicas in tank are shown in Figs. 22 and 23. The results showed that, the extrusion temperature has a significant effect on the roughness $\left(R_{\mathrm{a}}\right)$. It can be observed that an increase in the final extrusion temperature caused a slight decrease in the surface roughness of the materials. 
Under the same conditions, the lowest roughness was observed on COC replicas. There is directly related to the viscosity of the polymer.

(a) Elastomeric mould

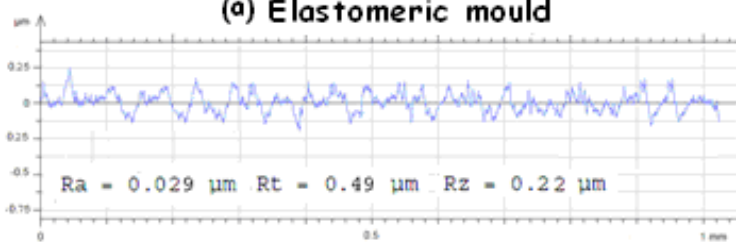

(b) Replica at $200^{\circ} \mathrm{C}$

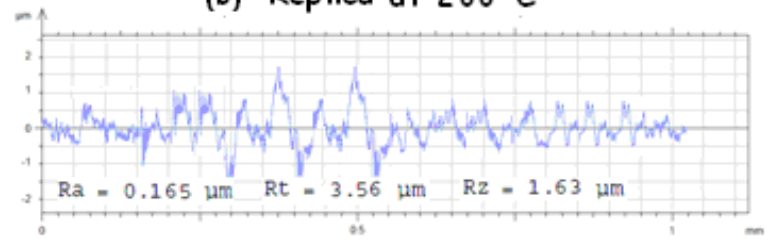

(c) Replica at $230^{\circ} \mathrm{C}$

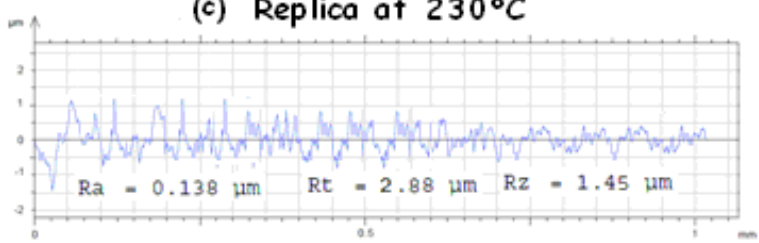

(d) Replica at $260^{\circ} \mathrm{C}$

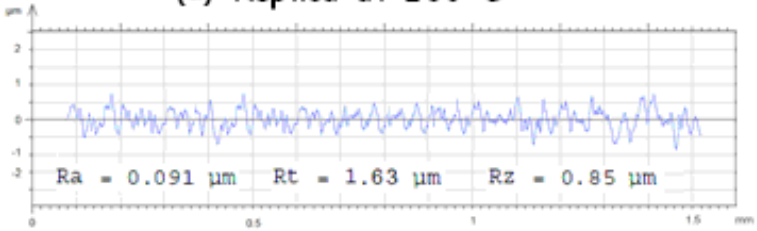

Figure 22. Effects of embossing temperature on the measuring surface roughness (polypropylene micro-fluidic replica using roller speed: $0.4 \mathrm{~m} / \mathrm{min}$ and pressure: $0.35 \mathrm{MPa}$ ).
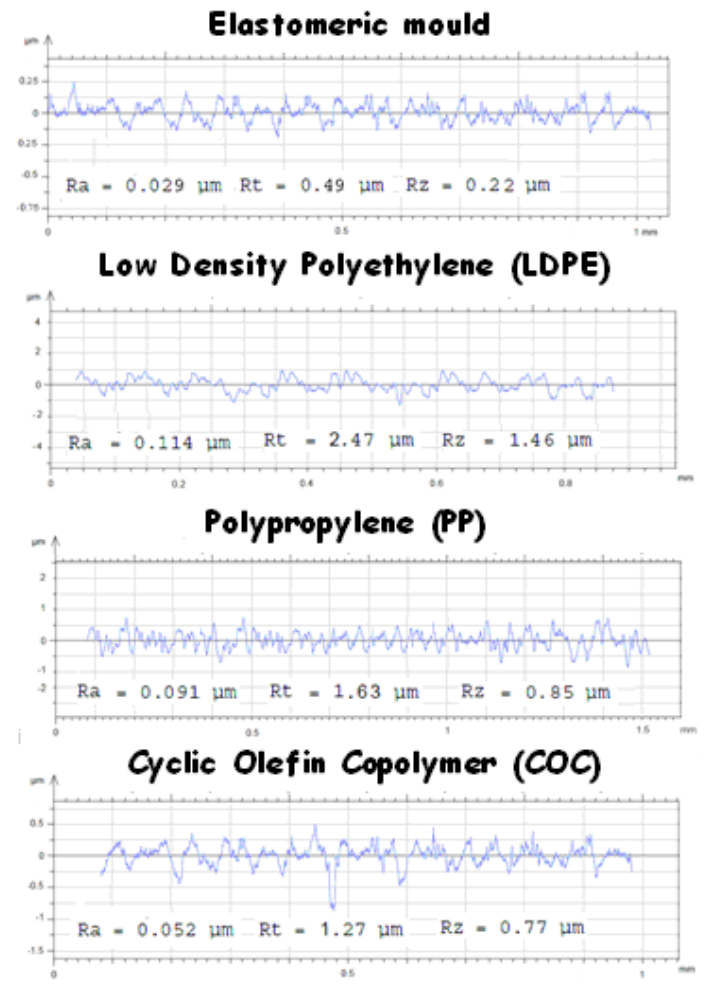

Figure 23. Evolution of the measuring surface roughness using different polymers (extrusion temperature: $260^{\circ} \mathrm{C}$, roller speed: $0.4 \mathrm{~m} / \mathrm{min}$ and pre ssure: $0.35 \mathrm{MPa}$ ). 


\section{Conclusions}

To address the increased demand for low-cost manufacturing of polymeric microfluidic devices, a very promising solution in the field of fabricating micro-structures via the roll embossing process can be used to perform polymer replication. This process has the advantage of high precision, simplicity, ease of operation, high production efficiency and low cost. This continuous roll embossing method and its principle were introduced in this paper. The critical parameters during the roll embossing process and the influence of these parameters on the accuracy of graph transfer were analysed.

In this work, we summarised the influence of the process parameters on the replication quality of the micro-structural feature transfer from the mould to the polymer substrate during the roll embossing process. Discussions were also included to explain some of the process phenomena, such as the incomplete filling and the defects due to substrate warping on the micro-channel corners. The data obtained by scanning mechanical microscopy (SMM) were used to determine the comparative filling ratio values. Based on the experimental results, three main conclusions can be drawn:

1. The temperature and uniformity of pressure were the two most important parameters for the embossing process and play a decisive role in the quality of the products. In addition, parameters such as the embossing speed and the plasticising quality of the polymer film also had an important impact on the quality of the embossing products,

2. The plastic film was held against the roller for some time for the purpose of microstructure conformity. Reducing the rolling speed increases the hold time and thus increases the replicability of the polymer substrates,

3. The overall performance of replication with proper microstructures using a paper conveyor belt was very much improved when compared to that using a rubber conveyor belt.

The results indicated that the micro-structure on the elastomeric roller was perfectly transferred to the polymer film. Finally, the proposed method shows great potential for the fabrication of micro-components due to its simplicity and versatility.

\section{Reference}

1. C. Khan Malek, L. Robert, G. Michel, A. Singh, M. Sahli, B. Gauthier Manuel, High resolution thermoplastic rapid manufacturing using injection moulding with SU-8 based silicon tools, CIRP J. Manuf. Sci. Technol. 4 (2011) 382-390.

2. X. Zhu, T. Cui, Polymer shrinkage of hot embossed microstructures for higher aspect ratio and smaller size, Sensors and Actuators A: Physical, 195 (2013) 2126.

3. M. Heckele, W. K. Schomburg, Review on micro molding of thermoplastic polymers, J Micromechan Microeng, 14 (2004) 1-14.

4. A.T. Sidambe, I. A. Figueroa, H.G.C. Hamilton, I. Todd, Metal Injection Moulding of CP-Ti Components for Biomedical Applications, J. Mater. Process. Technol. 212 (2012) 1591-1597. 
5. H. Becker, U. Heim, Hot embossing as a method for the fabrication of polymer high aspect ratio structures, J. Sens. Actuat. 83 (2000) 130-135.

6. M. Heckele, W. Bacher, K.D. Müller, Hot embossing - The molding technique for plastic microstructures, Microsyst. Technol., 4 (1998) 122-124.

7. M. Sahli, C. Millot, J.-C. Gelin, T. Barriere, The manufacturing and replication of microfluidic mould inserts by the hot embossing process, J. Mater. Process. Technol. 213 (2013) 913-925.

8. J.M. Li, C. Liu, H.C. Qiao, L. Y. Zhu, G. Chen, X.D. Dai, Hot embossing/bonding of a poly(ethylene terephthalate) (PET) microfluidic chip, J. Micromech. Microeng. (2008)18:015008.

9. W. Li, J. Greener, J. Ren, V. Pakharenko, D. Voicu, T. Tang, E. Kumacheva, Fabrication of Microfluidic Reactors in Thermoplastic Polymers by Combining Photo-lithography and Hot Embossing, Lab Chip 10 (2010) 522-524.

10. U. M. Attia, S. Marson, J. R. Alcock, Design and fabrication of a three-dimensional microfluidic device for blood separation using micro-injection moulding, Microfluid Nanofluid 7 (2009) 1-28.

11.T.E. Kimerling, W. Liu, B.H. Kim, D. Yao, Rapid hot embossing of polymer microfeatures, Microsyst. Technol. 12 (2006) 730-735

12.S.H. Ahn, L.J. Guo, High-Speed Roll-to-Roll Nanoimprint Lithography on Flexible Plastic Substrates, Adv. Mater., 20 (2008) 2044-2049.

13. C.-J. Ting, M.-C. Huang, H.-Y. Tsai, C.-P. Chou, C.-C. Fu, Low cost fabrication of the large-area anti-reflection films from polymer by nanoimprint/hot-embossing technology, Nanotechnol. 19 (2008) 1-5.

14. T. Velten, H. Schuck, W. Haberer, F. Bauerfeld, Investigations on reel-to-reel hot embossing, Int. J. Adv. Manuf. Technol. 47 (2010) 73-80.

15. L-P. Yeo, S-H. Ng, Z. Wang, Z. Wang, N. Frans de Rooij, Micro-fabrication of polymeric devices using hot roller embossing, Microelectro. Eng. 86 (2009) 933936.

16. C.Y. Chang, S. Y. Yang, J. L. Sheh, A roller embossing process for rapid fabrication of microlens arrays on glass substrates, Microsyst. Technol. 12 (2006) 754-759.

17.S. J. Liu, Y. C. Chang, A novel soft-mold roller embossing method for the rapid fabrication of micro-blocks onto glass substrates, J. Micromech. Microeng. 17 (2007) 172-179.

18. T. Makela, T. Haatainen, P. Majander, J. Ahopelto. Continuous roll to roll nanoimprinting of inherently conducting polyaniline, Microelectron. Eng. 84 (2007) 877-879.

19. K. Metwally, L. Robert, R. Salut, C. Khan-Malek, SU-8-based rapid tooling for thermal roll embossing, Microsyst. Technol. 18 (2012) 1863-1869.

20. C-W. Tsao, T-Y. Chen, W. Y. Woon, C-J. Lo, Rapid polymer microchannel fabrication by hot roller embossing process, Microsyst. Technol. 18 (2012) 713722.

21. T. Velten, H. Schuck, M. Richter, G. Klink, K. Bock, C. K. Malek, S. Roth, H. Schoo H, P. Bolt, Microfluidics on foil: state of the art and new developments, J. Eng. Manuf. 222 (2008) 107-116.

22. T. Kasahara, S. Matsunami, T. Edura, J. Oshima, C. Adachi, S. Shoji, J. Mizuno, Fabrication and performance evaluation of microfluidic organic light emitting diode, Sensors and Actuators A: Physical, 195(2013) 219-223.

23. H. Ahn, and L. J. Guo, High Speed Roll-to-Roll Nanoimprint Lithography on Flexible Plastic Substrate, Adv. Mater. 20 (2008) 2044-2049. 
24.S. H. Ng, Z. F. Wang, Hot roller embossing for microfluidics: process and challenges, Microsyst Technol. 15 (2009) 1149-1156.

25. X. C. Shan, L. Jin, Y. C. Soh, C. W. Lu, A polymer-metal hybrid flexible mould and application for large area hot roller embossing, Microsyst. Technol. 16 (2010) 1393-1398.

26. T. Velten, F. Bauerfeld, H. Schuck, S. Scherbaum, C. Landesberger, K. Bock, Roll-to-roll hot embossing of microstructures, Microsyst. Technol. 17 (2011) 619627.

27.H. Tan, A. Gilbertson, S. Y. Chou, Roller nanoimprint lithography, J. Vac. Sci. Technol. B. 16 (1998) 3926-3928.

28. D. Paul, A. Pallandre, S. Miserere, J. Weber, J. L. Viovy, Lamination-based rapid prototyping of microfluidic devices using flexible thermoplastic substrates, Electroph. 28 (2007) 1115-1122.

29. K.Metwally, S. Queste, L. Robert, R. Salut, C. Khan-Malek, Hot roll embossing in thermoplastic foils using dry-etched silicon stamp and multiple passes, Microelectro. Eng. 88 (2011) 2679-2682.

30. T. Mäkelä, T. Haatainen, Roll-to-roll pilot nanoimprinting process for backlight devices, Microelectro. Eng. 97 (2012) 89-91. 